\title{
Profiling the Genetic and Molecular Characteristics of Glanzmann Thrombasthenia: Can It Guide Current and Future Therapies?
}

\author{
Alan Nurden (iD) \\ Institut Hospitalo-Universitaire LIRYC, \\ Pessac, France
}

\begin{abstract}
Glanzmann thrombasthenia (GT) is the most widely studied inherited disease of platelet function. Platelets fail to aggregate due to a defect in platelet-to-platelet attachment. The hemostatic plug fails to form and a moderate to severe bleeding diathesis results. Classically of autosomal recessive inheritance, GT is caused by defects within the ITGA2B and ITGB3 genes that encode the $\alpha \operatorname{IIb} \beta 3$ integrin expressed at high density on the platelet surface and also in intracellular pools. Activated $\alpha \mathrm{IIb} \beta 3$ acts as a receptor for fibrinogen and other adhesive proteins that hold platelets together in a thrombus. Over 50 years of careful clinical and biological investigation have provided important advances that have improved not only the quality of life of the patients but which have also contributed to an understanding of how $\alpha \operatorname{IIb} \beta 3$ functions. Despite major improvements in our knowledge of GT and its genetic causes, extensive biological and clinical variability with respect to the severity and intensity of bleeding remains poorly understood. I now scan the repertoire of $I T G A 2 B$ and $I T G B 3$ gene defects and highlight the wide genetic and biological heterogeneity within the type II and variant subgroups especially with regard to bleeding, clot retraction, the internal platelet Fg storage pool and the nature of the mutations causing the disease. I underline the continued importance of gene profiling and biological studies and emphasize the multifactorial etiology of the clinical expression of the disease. This is done in a manner to provide guidelines for future studies and future treatments of a disease that has not only aided research on rare diseases but also contributed to advances in antithrombotic therapy.
\end{abstract}

Keywords: Glanzmann thrombasthenia, inherited platelet disorder, bleeding syndrome, integrin, gene profiling, mutation analysis

\section{Introduction}

In Glanzmann thrombasthenia (GT) (OMIM\#273,800) platelets fail to aggregate when stimulated by physiologic agonists while clot retraction is often defective. ${ }^{1}$ Platelets interact with exposed subendothelium but a platelet-rich hemostatic plug fails to form. Spontaneous or trauma-dependent mucocutaneous bleeding is usually observed from birth. Epistaxis, gum bleeding, easy bruising, ecchymoses and petechiae are frequent and gastro-intestinal (GI) bleeding is a major problem particularly in older patients. ${ }^{2,3}$ Menorrhagia is critical for women while pregnancy and childbirth present severe hemorrhagic risks. Surgery including tooth extraction requires preventative measures. The molecular basis of GT was clarified when, in Paris, I located a deficit of two major platelet membrane glycoproteins (GPs) in this disease. $^{4}$ As the complexity of the platelet surface topography became apparent
Correspondence: Alan Nurden Institut Hospitalo-Universitaire LIRYC, Pessac, 33600, France

Email nurdenat@gmail.com 
these were named GPIIb and GPIIIa; it was quickly realized that they form a $\mathrm{Ca}^{2+}$-dependent complex in platelets. $^{5-7}$

The inability of GPIIb-IIIa to bind fibrinogen (Fg) or other adhesive proteins accounts for the lack of aggregation in GT. Clinical and biological heterogeneity led to the definition of three subgroups (type I, type II and variant forms) largely depending on the ability of platelets to retract a clot, store Fg and the level of GPIIb-IIIa expression (Table 1). A major advance came when GPIIb-IIIa was revealed as $\alpha \mathrm{IIb} \beta 3$, a member of the integrin superfamily of cellular receptors (reviewed by Coller and Shattil ${ }^{8}$ ). Electron microscopy initially showed GPIIb-IIIa to have a head and two legs; later crystallography strikingly revealed $\alpha \mathrm{IIb} \beta 3$ in a bent conformation that on activation straightened as it took on its ligand-binding conformation. $^{8-10}$ Precision crystallography and modeling showed $\alpha$ IIb and $\beta 3$ to have precisely defined subdomains (shown in Figure 1).
ITGA2B (OMIM \# 607,759) with 26 exons and ITGB3 (OMIM \# 173,470) with 15 exons encode $\alpha \mathrm{IIb}$ and $\beta 3$; both genes localizing to a $260-\mathrm{kb}$ segment on the long arm of chromosome 17. ${ }^{11,12}$ In pioneering work, Newman et al showed that GT was caused by defects in either gene with in Israeli-Arabs a founder ITGA2B mutation (c.IVS3(-3)418del + frameshift (Fs)) while in Iraqi-Jewish patients there was a c.2031-2041del/premature termination in ITGB3. ${ }^{13}$ Over the years, several hundred mutations with AR inheritance have been identified in GT including small deletions and insertions and splice site variants causing a Fs as well as abundant nonsense and missense mutations sometimes also associated with mRNA instability. ${ }^{14-16}$ While repeated mutations may identify gene hotspots, others within ethnic groups are clearly founder mutations; yet for most families they remain private. Large deletions are rare. ${ }^{17}$ In addition to $\alpha \mathrm{IIb} \beta 3$, platelets contain trace amounts of $\alpha v \beta 3$ mostly lacking when the genetic lesion affects $I T G B 3$ but persisting and even in increased density

Table I Glanzmann Thrombasthenia in All Its Forms

\begin{tabular}{|c|c|}
\hline Disease Description & Comments \\
\hline \multicolumn{2}{|l|}{ Type I Subgroup } \\
\hline $\begin{array}{l}\text { - Absence of platelet aggregation and little or no clot retraction. Levels } \\
\text { of } \alpha \text { llb } \beta 3<5 \% \text { or absent. Platelet Fg storage pool lacking or negligible. } \\
\text { AR inheritance. }\end{array}$ & $\begin{array}{l}\text { - The most common type of GT, given by defects in ITGA2B and ITGB3 } \\
\text { genes. With ITGA2B defects } \alpha \mathrm{v} \beta 3 \text { may still be present and functional. } \\
\text { Patients susceptible to form isoantibodies reactive with } \alpha \text { llb } \beta 3 \text { and/or } \\
\alpha v \beta 3 \text { after blood transfusion or pregnancy. }\end{array}$ \\
\hline \multicolumn{2}{|l|}{ Type II Subgroup } \\
\hline $\begin{array}{l}\text { - Absence of platelet aggregation but clot retraction can be partial or } \\
\text { normal. Residual } \alpha \text { llb } \beta 3 \text { historically defined as } 5-15 \% \text { of normal levels. } \\
\text { Platelet Fg pool can be substantial. AR inheritance. }\end{array}$ & $\begin{array}{l}\text { - Frequency variable within populations but usually less than } 20 \% \text { of the } \\
\text { patients. Given by defects in ITGA2B and ITGB3. Clot retraction defects } \\
\text { and the platelet Fg storage capacity are mutation dependent. }\end{array}$ \\
\hline \multicolumn{2}{|l|}{ Variant Forms } \\
\hline $\begin{array}{l}\text { - Absence of platelet aggregation but clot retraction and } \mathrm{Fg} \text { storage } \\
\text { highly variable. Residual } \alpha \text { llb } \beta 3 \text { mainly }>50 \% \text { or even normal but non- } \\
\text { functional with little or no activation-dependent } \mathrm{Fg} \text { binding as also } \\
\text { shown by a lack of PAC-I binding. AR inheritance. }\end{array}$ & $\begin{array}{l}\text { - Rare. Can be given by defects in ITGA2B but mostly by ITGB3 variants. } \\
\text { Extracellular mutations directly or indirectly abrogate Fg-binding sites. } \\
\text { Intracellular mutations stop signals for } \alpha \text { llb } \beta 3 \text { activation. Clot retraction } \\
\text { and Fg storage are mutation dependent. Can be confused with defects in } \\
\text { FERMT3 and RASGRP2 that prevent kindlin-3 (LAD-III disease) and } \\
\text { CaIDAG-GEFI signaling. }\end{array}$ \\
\hline \multicolumn{2}{|l|}{ Upregulated $\alpha \mathrm{llb} \beta 3$ and Macrothrombocytopenia (MTP) } \\
\hline $\begin{array}{l}\text { - Much reduced platelet aggregation with clot retraction and Fg storage } \\
\text { again variable. Residual } \alpha \mathrm{llb} \beta 3 \text { normally }>30 \% \text { but with spontaneous } \\
\text { binding of PAC-I (but rarely Fg). MTP mostly moderate with } \\
\text { subpopulations of enlarged even giant platelets. AD inheritance. }\end{array}$ & $\begin{array}{l}\text { - Rare. Patients with up-regulated } \alpha \text { llb } \beta 3 \text { interfering with megakaryocyte } \\
\text { maturation and platelet biogenesis with enlarged platelets in variable } \\
\text { numbers. Bleeding mostly due to defective } \alpha \text { llb } \beta 3 \text { function. Single allele } \\
\text { mutations on ITGA2B but mostly ITGB3. Often these affect cytoplasmic } \\
\text { domains. }\end{array}$ \\
\hline
\end{tabular}

Notes: The above criteria are basic for each subtype, but there is much overlap between them and clear boundaries do not exist. PAC-I is an activation dependent IgM monoclonal antibody to $\alpha$ llb $\beta 3$.

Abbreviations: AR, autosomal recessive; AD, autosomal dominant; LAD-III, leukocyte adhesion deficiency syndrome type III. 
Integrin in its bent resting state. On activation it straightens at the knee exposing the epitopes on the integrin head that bind $\mathrm{Fg}$ and other ligands

Transmembrane domains mediate the transfer of signals necessary for inside-out and outside-in signaling and integrin activation

Cytoplasmic domains assure the binding of talin and kindlin-3 esential for integrin activation. They also mediate the interaction with the cytoskeleton

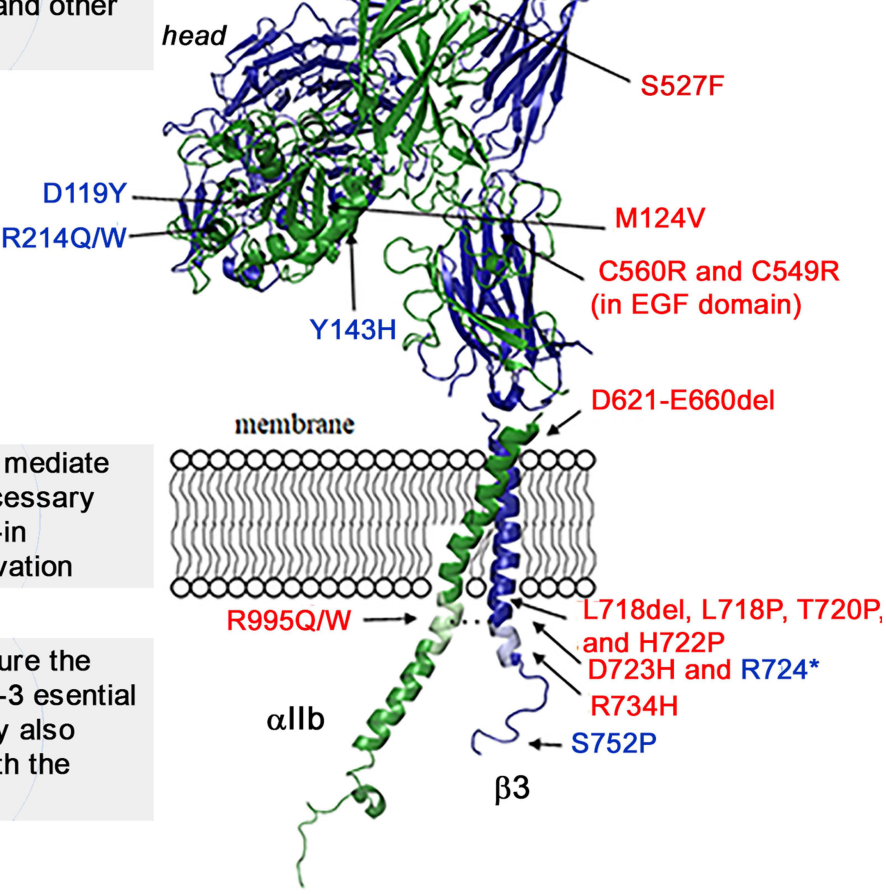

Figure I Structural representation of $\alpha$ llb $\beta 3$ in its bent conformation showing the mutations that give rise to selected variant forms of GT or to related phenotypes. This model is based on the crystal structure of $\alpha$ llb $\beta 3$; it was constructed using the PyMol Molecular Graphics System, version I.3 Schrödinger, LLC and 3fcs and $2 \mathrm{knc}$ pdb files as described. ${ }^{16}$ The $\alpha$ llb subunit is in green and $\beta 3$ is in blue. Precision crystallography and modeling showed that $\alpha$ llb has 4 major extracellular domains ( $\beta$-propeller, thigh, calf$I$ and calf-2) whereas $\beta 3$ has more ( $\beta$-I or $\beta$-A, hybrid, plexin-semaphorin-integrin (PSI), 4 epidermal growth factor (EGF) and the $\beta$-tail domain). 8 .I0 Loss-of-function mutations (in blue) in the $\beta 3$ extracellular head prevent binding of $\mathrm{Fg}$ or other adhesive proteins to the opened integrin headpiece following platelet activation, while those in the $\beta 3$ cytoplasmic tail prevent binding of kindlin-3 and/or talin, and block steps essential for integrin activation. Gain-of-function mutations (in red) lead to at least partial activation of $\alpha$ llb $\beta 3$ and often associated with MTP accompanied by a variable loss of $\alpha$ llb $\beta 3$ function. All mutations are detailed and referenced in the text.

when ITGA2B mutations are the cause. ${ }^{18}$ While $\alpha \operatorname{IIb} \beta 3$ is more or less specific for MKs and platelets, $\alpha \mathrm{v} \beta 3$ through the more promiscuous translation of $I T G B 3$ is widespread but without influencing the bleeding phenotype in GT. ${ }^{19}$

An objective of this review is to question whether in 2021 it is valid to classify GT into distinct subgroups. In so doing, I ask 1) what are the genetic causes allowing the expression of residual $\alpha \operatorname{IIb} \beta 3,2$ ) whether this residual $\alpha \operatorname{IIb} \beta 3$ is functional, and 3 ) whether type II and variant GT give rise to a milder form of GT. Likewise, I ask how the advent of high-throughput sequencing procedures can be used to better advantage in determining patient care.

\section{Biological Testing Within the Type I and Type II Subgroups}

Diagnosis of GT is straightforward given the clinical characteristics and phenotype as revealed by platelet function and biological testing. Platelets fail to form large aggregates in response to physiologic agonists in a platelet aggregometer although small clusters were noted by microscopy. ${ }^{1}$ Using flow cytometry (FC), others showed how GT platelets formed small aggregates when interacting with collagen through the $\alpha 2 \beta 1$ receptor. ${ }^{20}$ Ristocetininduced platelet agglutination (RIPA) mediated through the binding of VWF to GPIb is mostly normal in GT but can be reversible or occur in cycles. Clot retraction provides useful information on the type II and variant forms while measuring the closure time in the point-of-care Platelet Function Analyzer-100 (PFA-100) has largely replaced the bleeding time. Highly recommended for patient management is the International Society of Thrombosis and Haemostasis-Bleeding Assessment Tool (ISTH-BAT) that uses a standardized questionnaire to enable the clinician to establish a comprehensive clinical file. ${ }^{21}$ 
An inherent difficulty in characterizing type II and variant GT is accurately measuring $\alpha \operatorname{IIb} \beta 3$ expression on platelets. Currently, the binding of monoclonal antibodies (MoAbs) is assessed directly or indirectly by FC. However, copy number can be influenced by bivalent IgG MoAbs cross-linking adjacent $\alpha \operatorname{IIb} \beta 3$ complexes; a less likely occurrence at a low surface density of $\alpha \operatorname{Ilb} \beta 3$ and although the use of Fab fragments is advisable their use is rare. The genetic variants causative of GT can also influence MoAb binding, either directly or through long-range allosteric effects. Thus, measures are approximate and many groups report results for a combination of MoAbs to different epitopes as well as performing Western blotting (WB) but as this review will underline the results are frequently disparate. Overlap of $\alpha \operatorname{Ilb} \beta 3$ density between heterozygotes and normal donors confuses family studies. Key to understanding the heterogeneity within the type II and variant subgroups is to determine the degree to which the residual $\alpha \operatorname{IIb} \beta 3$ is functional (Table 1).

\section{Ethnic Groups}

While an estimate of 1 per million is the often given frequency of GT, it is more common in certain ethnic groups where consanguinity prevails. These include Jewish and Arab groups in Israel, French Manouche gypsies, and rural communities in India and Iran. ${ }^{13,22-24}$ Studies on the French gypsies initially concerned the Strasbourg area in France; focussing on ITGA2B in view of trace amounts of $\beta 3$ in $\mathrm{WB}$, the authors identified a c. $1544+1 \mathrm{G}>\mathrm{A}$ substitution at the $5^{\prime}$ splice donor site of intron $15 .^{22}$ The result was an 8 -bp deletion at the $3^{\prime}$-end of exon 15, a premature stop codon and a severely truncated $\alpha \mathrm{IIb}$. Analysis of family members revealed a strong association between a haplotype of five polymorphic loci covering a 4-cm region and the mutation suggesting a founder effect dating back to $300-400$ years. ${ }^{25}$ More recently, Zhou et $\mathrm{al}^{26}$ screened 93 families with GT within the Chinese Han population with a lower level of consanguinity (18\%) than other ethnic groups where GT is prevalent. Significantly, $74 \%$ of the patients had type I GT, $24 \%$ type II and only $2 \%$ had a variant form. A total of 43 genetic variants were identified. As had been noted earlier, patients with the same genotype sometimes presented with markedly different bleeding severities. $^{2,17}$

\section{Missense Mutations and Biological Heterogeneity of Type II GT}

The type II subgroup is highly heterogeneous with respect to the amount of residual $\alpha \operatorname{IIb} \beta 3$, the genetic cause, the functionality of the residual integrin, and bleeding severity. The selected case reports detailed and summarized in Suppl Table I reflect this. The results show how the mechanism by which $\alpha \operatorname{IIb} \beta 3$ binds Fg after activation and its capture and storage in $\alpha$-granules is clearly different. Neither is there a clear relationship between the ability of platelets to capture Fg and retract a clot, contradicting historical reports. ${ }^{2,3}$ Also, variable is adhesion to surface-bound Fg, mostly studied using transfected cells.

\section{Patients with ITGA2B Defects}

The first patients genotyped for type II GT were independently described and concerned a homozygous p.R327H substitution in $\alpha \mathrm{IIb} .^{27,28} \mathrm{~A}$ twofold difference in residual platelet $\alpha \operatorname{IIb} \beta 3$ content between the probands suggests an influence of other undefined factors. The maturation or trafficking of pro- $\alpha \operatorname{IIb} \beta 3$ was shown to be impaired in transfected COS-7 or Chinese Hamster Ovary (CHO) cells. A homogeneous ITGA2B p.L183P mutation in a man with severe bleeding illustrates the difficulties of evaluating $\alpha \mathrm{IIb} \beta 3$ expression in some cases. ${ }^{29}$ While complex-dependent MoAbs bound minimally, WB revealed $30-35 \%$ of each subunit with $\alpha$ IIb showing signs of proteolysis. Platelet $\alpha v \beta 3$ was somewhat increased. Expressed in $\mathrm{CHO}$ cells the surface expression of the mutated $\alpha \operatorname{Ilb} \beta 3$ was $60 \%$ as measured using subunit-specific MoAbs, whereas complex-dependent MoAbs or the activationdependent MoAb, PAC-1, bound minimally. Both of the above mutations concerned the $\alpha \mathrm{IIb} \beta$-propeller.

Ambo et $\mathrm{al}^{30}$ reported two Japanese women with platelets having residual $\alpha \operatorname{IIb} \beta 3$ who were homozygous for $p$. Q747P affecting the $\alpha$ IIb calf-2 domain. Platelets attached to surface-bound Fg at intermediate levels; clot retraction was near normal. In fact, p.Q747P is a founder mutation for type II GT in Japan. While other homozygous patients had a similar phenotype, compound heterozygosity combining p.Q747P and a splice site mutation leading to exon 18 skipping gave a lower $4-8 \% \alpha$ IIb $\beta 3$ expression. ${ }^{31}$ In $\mathrm{CHO}$ cells $\alpha \mathrm{IIbP747 \beta 3}$ bound $\mathrm{Fg}$ in the presence of an activating MoAb. Pulse-chase labeling with (35S)methionine showed that its maturation was impaired. Next to be published was a young Spanish girl with 
lifelong bleeding; her platelets had 10\% residual $\alpha \mathrm{IIb} \beta 3$, low platelet Fg, but supported a much-reduced clot retraction. $^{32}$ She was compound heterozygous for a paternal splice site variant $\operatorname{IVS} 5(+2) \mathrm{C}->\mathrm{A}$ transversion predicting a truncated protein and highly unstable mRNA, and a maternal p.C674R substitution that disrupted a disulfide bridge. Her heterozygous mother had platelets with only $30 \%$ of normal levels suggesting that her mutation had a dominant-negative effect. Expression of $\alpha$ IIbR674 33 in CHO cells confirmed the platelet phenotype with intracellular retention of pro- $\alpha \mathrm{IIbR} 674$ by the chaperone BiP explaining a reduced transport to the Golgi apparatus and then to the surface membrane. ${ }^{33}$

Basani et $\mathrm{al}^{34}$ reported type II GT linked to an ITGA2B p.P145L mutation reoccurring in families of American, Dutch and Chinese origins with mild to severe bleeding. Two Mennonite siblings had platelets with residual $\alpha \operatorname{IIb} \beta 3$ unable to bind PAC-1 and with a much-reduced Fg storage pool. Expression of $\alpha \mathrm{IIb} \beta 3$ was lower or absent in the Dutch and Chinese families with compound heterozygosity $(5 \%$ and $<1 \%$, respectively, $)$ again illustrating how second allele mutations help program $\alpha \mathrm{IIb} \beta 3$ density. For the Chinese patient, p.P145L was given by a different nucleotide change. Mutation scanning of aIIbP145 in transfected COS-1 cells showed that only p.P145K abrogated $\alpha \mathrm{IIb}$ synthesis, while other mutants including $\mathrm{p}$. P145L allowed pro- $\alpha \operatorname{IIb} \beta 3$ formation but interfered with maturation. Highly conserved, P145 locates to the upper surface of the $\beta$-propeller and is adjacent to the W3:4.1 loop identified as a potential ligand-binding site by

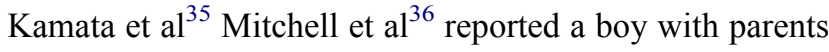
from Puerto Rico and Canada and with platelets containing $3-6 \%$ aIIb $\beta 3$ and an Italian/Sicilian family where MoAb binding showed $7-8 \% \alpha \mathrm{IIb} \beta 3$ for four family members. As few clinical and biological details were given these cases are not included in Suppl Table I. For both families, $\alpha v \beta 3$ was unaffected and WB confirmed residual mature $\alpha \mathrm{IIb}$ and $\beta 3$ in their platelets. The American proband was compound heterozygous for p.V298F near the second $\mathrm{Ca}^{2+}$-binding domain in blade 5 of the $\alpha \mathrm{IIb} \beta$-propeller, and p.Y380* that prevents $\alpha \mathrm{IIb}$ expression. The Sicilian family combined p.C674R in the $\alpha$ IIb calf- 1 domain and a p.I374T missense mutation within the third $\mathrm{Ca}^{2+}$-binding domain in blade 6 of the $\beta$-propeller. Interestingly, his father was homozygous for p.C674R while his children were compound heterozygous for both mutations. When the two $\beta$-propeller missense mutations were expressed in recombinant $\alpha \mathrm{IIb} \beta 3$ in $293 \mathrm{~T}$ cells pulse-chase experiments showed much of the mutated pro- $\alpha$ IIb to be retained in the ER. Jayo et $\mathrm{al}^{37}$ described a 2-year-old girl of Chinese nationality with lifelong bleeding, no platelet aggregation or clot retraction but with platelet $\mathrm{Fg}$ in the normal range. Her platelets expressed $<10 \%$ residual $\alpha \operatorname{IIb} \beta 3$ but $\alpha v \beta 3$ was normally present. Residual Fg binding indicated a qualitative defect. Sequencing of reverse-transcribed aIIb mRNA revealed compound heterozygosity: a c. C2829T transition giving a p.P912L substitution within the $\alpha \mathrm{IIb}$ light chain and a c.C1750T transition in exon 17 of $I T G A 2 B$ that gave p.R553* predicting truncated $\alpha \mathrm{IIb}$ but also nonsense-mediated decay. The object of multiple reports in Asian patients, p.R553* is clearly a mutational hotspot. Transfection in $\mathrm{CHO}$ cells showed that $\alpha \operatorname{IIb} \beta 3 \mathrm{~L} 912$ reaches the surface but with a fivefold reduction in the rate of expression. Enigmatically, exontrap analysis of the mutant $\alpha \mathrm{IIb}$ alleles in $\mathrm{CHO}$ cells showed that c.C2829T was also forcing skipping of exon 28; nonetheless, despite mRNA lacking exon 28 being present in platelets, the residual platelet $\alpha$ IIbL912 $\beta 3$ only concerned the full-length transcript.

More recent studies using in silico analysis and molecular dynamics simulations of variants affecting the $\alpha \mathrm{IIb}$ calf-1 domain showed dynamic allosteric effects and that were mostly long range. ${ }^{38}$ But of the seven variants studied, only the above-mentioned p.C674R mutation gave type II GT. Pillois et $\mathrm{al}^{39}$ also reviewed structural modifications in and around the $\alpha \mathrm{IIb}$ genu, a region that is the fulcrum of the bent "resting" state of $\alpha \operatorname{IIb} \beta 3$. This literature survey covered mutations extending from the lower part of the $\beta$-propeller through the thigh and upper calf-1 domains identifying 37 cases involving 16 missense mutations all causal of type I GT with only p.A446P (within the seventh blade of the $\beta$-propeller) and p.C674R allowing $\alpha \mathrm{IIb} \beta 3$ expression and type II GT. Static in silico modeling confirmed how modifications of structuring $\mathrm{H}$-bonds were the major cause of GT in the thigh domain, whereas in calf-1 long-range effects predominated.

\section{Patients with ITGB3 Defects}

The first reported $\beta 3$ mutation in a type II patient concerned a Chinese girl from a consanguineous family with a lifelong history of severe bleeding. ${ }^{40}$ Clot retraction was absent, but platelet Fg was $36 \%$ of normal. Platelet $\alpha \mathrm{IIb} \beta 3$ expression was reduced to $6-14 \%$ and $\alpha v \beta 3$ was likewise reduced. Sequencing of PCR-amplified cDNA identified a homozygous p.C374Y mutation in ITGB3. Transient transfection in $\mathrm{CHO}$ cells confirmed a $85-90 \%$ reduction in the 
surface expression of the mutated $\alpha \mathrm{IIb} \beta 3$ yet the cells retained an ability to attach to surface-bound Fg. Novel integrin $\beta 3$ subunit missense mutations were then reported for unrelated Japanese patients with type II GT and lifelong mild bleeding. ${ }^{41}$ For all patients, platelet aggregation was absent but clot retraction was in the normal range. Platelet expression of $\alpha \mathrm{IIb} \beta 3$ ranged from $7.5 \%$ to $20 \%$. The first patient, an elderly woman, was homozygous for p.H280P while the second and third patients, both male, were compound heterozygous for the same mutation combined with $\mathrm{p}$. G579S and p.C560F, respectively, both in the EGF-3 domain. When expressed in $\mathrm{CHO}$ cells there was a significantly reduced $\alpha \mathrm{IIb} \beta 3$ expression for $\mathrm{p} . \mathrm{H} 280 \mathrm{P}$ and p.G579S but surprisingly a near normal expression for $\mathrm{p}$. $\mathrm{C} 560 \mathrm{~F}$. The expression of $\alpha \mathrm{v} \beta 3$ in the $\mathrm{CHO}$ cells was also affected. Preliminary information was provided that $\mathrm{p}$. C560F and p.G579S in the EGF-3 domain were activating mutations, but their contribution to the residual $\alpha \operatorname{IIb} \beta 3$ on the patients' platelets is unknown. Other cases in Japan have since been reported to have the p.H280P variant which may represent a founder mutation.

A girl whose mother was diagnosed with von Willebrand disease (VWD) had lifelong bleeding but normal plasma VWF levels and platelets that agglutinated with ristocetin but which failed to aggregate with physiologic agonists. ${ }^{42}$ Her platelets bound subnormal amounts of subunit-specific MoAbs to $\alpha \mathrm{IIb}$ and $\beta 3$ yet bound neither AP-2, a complex-specific MoAb nor on activation did they bind Fg. Western blotting confirmed about $10 \%$ of control platelet levels of normally migrating $\alpha \mathrm{IIb}$ and $\beta 3$. Notwithstanding, her platelets mediated a normal clot retraction. The patient was compound heterozygous for mutations in ITGB3 thereby showing how two inherited platelet disorders (IPDs) can occur in the same family. A paternal c.G867C868 dinucleotide deletion was predicted to give a Fs and a stop codon at p.Q267; a 50\% expression of normally sized $\alpha \mathrm{IIb} \beta 3$ in her father's platelets confirmed the non-expression of the truncated $\beta 3$. Her second mutation was a missense p.L262P substitution; the introduction of a proline $(\mathrm{P})$ was predicted to introduce a $\beta$-turn and to alter $\beta 3$ conformation. In transfected cells, $\alpha \mathrm{IIb} \beta 3 \mathrm{P} 262$ was unstable and only small amounts reached the surface. Pulse-chase experiments confirmed that $\alpha I I b \beta 3 P 262$ formed in the ER, but that maturation was markedly delayed. The cells retracted a fibrin clot but failed to bind to immobilized Fg although normally attaching to and spreading on Fn and Vn. Nair et $\mathrm{al}^{43}$ described a young boy with bleeding since birth. His platelets bound only trace amounts of MoAbs to $\alpha \mathrm{IIb} \beta 3$, but in WB $\alpha \mathrm{IIb}$ and $\beta 3$ were $10 \%$ to $30 \%$ of normal, unusually his $\beta 3$ migrated as a high molecular weight band, thought to be $\beta 3$ dimer as its migration normalized after disulfide reduction. Platelet Fg was $<20 \%$ of normal. He was homozygous for a p.C506Y mutation in $\beta 3$; this created an unpaired cysteine in the EGF-2 region. Different models proposed that C506 could link with C495 or C501 in $\beta 3$.

An elderly Afghanistan woman from a consanguineous family had a lifelong history of mucocutaneous bleeding. ${ }^{44}$ Platelet aggregation was absent and clot retraction only $10 \%$ of normal; platelet adhesion to immobilized Fg was much reduced with the residual interaction blocked by an $\alpha \mathrm{IIb} \beta 3$ antagonist. Her platelets expressed $\alpha \mathrm{IIb} \beta 3$ at $24 \%$ of normal levels by FC but failed to bind Fg or PAC-1 after activation with ADP. Thus, once more, the residual $\alpha \operatorname{IIb} \beta 3$ had both quantitative and qualitative defects. Platelet Fg was virtually absent. Sequencing of cDNA revealed a homozygous p.T176I mutation in $I T G A 2 B$. Interestingly, $\alpha$ IIbI176 locates to the blade 3 1:2 loop of the $\alpha \mathrm{IIb} \beta$-propeller suggesting that it induces conformation changes through allosteric effects rather than direct interference. Expression of the mutated $\alpha \mathrm{IIb} \beta 3$ in COS-7 or CHO cells was confirmed as being much reduced.

Morel-Kopp et $\mathrm{al}^{45}$ reported a homozygous p.L196P $\beta 3$ variant in a French woman with type II GT and mild bleeding. Her platelets expressed only 4100 copies of $\alpha \operatorname{IIb} \beta 3$ yet her intra-platelet pool of $\mathrm{Fg}$ was as high as $50 \%$. A low expression of $\alpha \mathrm{IIb} \beta 3 \mathrm{P} 196$ was confirmed in transfected $\mathrm{CHO}$ cells with increased cytoplasmic pro$\alpha \mathrm{IIb}$ suggesting altered pro- $\alpha \mathrm{IIb} \beta 3$ processing. Intriguingly, cells expressing $\alpha \mathrm{v} \beta 3 \mathrm{P} 196$ failed to attach to surface-bound Fg, spread, form focal contacts, phosphorylate FAK (focal adhesion kinase) or retract a fibrin clot; events that were normal for cells with $\alpha \mathrm{IIb} \beta 3$ P196. Nevertheless, $\alpha$ IIb $\beta 3$ P196 failed to bind soluble Fg or PAC-1 when incubated with an activating MoAb. A second French family heterozygously expressing p. L196P and followed by us in Bordeaux had a similar phenotype. The proband, an elderly man with lifelong bleeding, had platelets with $8 \% \alpha \operatorname{IIb} \beta 3$ but WB again revealed a substantial pool of Fg a finding suggestive of $\alpha \mathrm{IIb} \beta 3$ recycling. His mother, a sister and son, all heterozygous for $\beta 3$ p.L196P had platelets with intermediate levels of $\alpha \operatorname{IIb} \beta 3$. A predicted second mutation in the proband was confirmed when later DNA sequencing revealed a p.C598Y substitution. ${ }^{15,17}$ Previously reported 
for a French type II patient, p.C598Y was said to be partially activated. ${ }^{46}$ Thus, the Bordeaux patient is an example of type II GT given by compound heterozygosity for two contrasting mutations each of which contributes to residual $\alpha \operatorname{IIb} \beta 3$ expression.

\section{Splice Site and Other Mutations in Type II GT}

Mutations in the calf- 1 and calf- 2 domains of $\alpha \mathrm{IIb}$ are not directly involved in ligand binding, but small discontinuous contacts link them to the EGF-3, EGF-4 and $\beta$-tail domains of $\beta 3 .^{47,48} \mathrm{~A}$ del-insert in exon 25 localizing to calf-2, and a transition in the acceptor splice site of intron 19 leading to in-frame skipping of exon 20 and affecting calf-1, resulted in type II GT. ${ }^{49}$ In each case, the mutated pro- $\alpha \mathrm{IIb}$ complexed with $\beta 3$ in transfected BHK cells, but little mature $\alpha \mathrm{IIb}$ resulted. Golgi mediated complex mannose glycosylation was not seen and immunolocalization confirmed that mutated $\alpha \mathrm{IIb} \beta 3$ was mostly retained in the ER. A homozygous c. $2348+5 \mathrm{G}>\mathrm{C}$ transversion in intron 23 of ITGA2B in an elderly male with type II GT (case 8 in the series reported by Nurden et $\mathrm{al}^{17}$ ) retained attention. Skipping of exon 23 was confirmed using a hybrid minigene transfection assay. Real-time PCR and specific primers showed major changes in spliced mRNAs together with a residual full transcript leading to the continued presence of $8-10 \%$ functional $\alpha \mathrm{IIb} \beta 3$ in his platelets. Although his platelets failed to aggregate, clot retraction was partial and platelet Fg was abundant and suggestive of $\alpha \operatorname{Ilb} \beta 3$ recycling. Despite his residual $\alpha \operatorname{IIb} \beta 3$, he had severe bleeding when young receiving arm-to-arm transfusions in wartime. Much later, when elderly, he had severe GI bleeding. A Moroccan girl from a consanguineous marriage with frequent petechia, bruising and mucocutaneous hemorrhages possessed platelets with about $10 \%$ $\alpha \operatorname{IIb} \beta 3$ that bound $\mathrm{Fg}$ in small amounts when stimulated. ${ }^{50}$ A homozygous c.G188A substitution at the splice donor site of intron 1 led to the use of alternative intronic donor sites leading to both a stop codon and nonsense-mediated decay and accounting for the low expression of $\alpha \mathrm{IIb} \beta 3$ in her platelets.

\section{Mutations Reducing $\alpha$ llb $\beta 3$ Expression and Overlapping That of Variant Forms}

The classification of type I; type II and variant GT on $\alpha \operatorname{Ilb} \beta 3$ numbers alone is purely arbitrary for borderline cases. For example, Jackson et $\mathrm{al}^{51}$ described a girl with platelets unable to bind Fg or aggregate when stimulated but with a normal clot retraction. Her platelets expressed $27 \% \alpha \mathrm{IIb}, 16 \% \beta 3$ with subunit-specific MoAbs, but with minimal binding of MoAbs to complex-dependent epitopes. In WB, her platelets contained about $30 \%$ of the normal levels of each subunit. Her $\alpha \operatorname{IIb} \beta 3$ was unstable and failed to express LIBS-binding sites when challenged. She had a homozygous p.S162L substitution in $\beta 3$ with a destabilizing effect on $\alpha \mathrm{IIb} \beta 3$. Highly conserved, S162 lies between the metal ion-dependent adhesion site (MIDAS) domain and a ligand regulatory loop near the socalled synergistic metal ion-binding site (SyMBS) of $\beta 3$. Expression of mutated $\alpha \mathrm{IIb} \beta 3 \mathrm{~L} 162$ in COS-7 cells led to pro- $\alpha \operatorname{IIb} \beta 3$ synthesis but delayed maturation with only small amounts of mature $\alpha \mathrm{IIb} \beta 3$ and a rapid proteolysis of both subunits. This patient nicely emphasizes how the $\alpha \mathrm{IIb} \beta 3$ determinants responsible for platelet aggregation and clot retraction are distinct. Platelets of a young Japanese woman (Osaka-12) with moderate mucocutaneous bleeding also sustained a residual clot retraction despite failing to aggregate. ${ }^{52}$ Her platelets expressed $36-41 \% \alpha \mathrm{IIb}$ and $\beta 3$ as assessed using MoAbs to the subunits but bound only $13 \%$ of a complex-dependent MoAb. Her $\alpha \operatorname{IIb} \beta 3$ failed to bind PAC- 1 when activated and aberrantly expressed LIBS epitopes. She was compound heterozygous for a p.Y143H substitution in the W3 4-1 loop of the $\alpha$ IIb $\beta$-propeller and a null allele; the latter largely accounting for the low $\alpha \operatorname{Ilb} \beta 3$ density. Transfected HEK cells normally expressed $\alpha I I b H 143 \beta 3$ but failed to bind PAC-1 or Fg in the presence of an activating MoAb. Identical results obtained for $\alpha I I b A 143 \beta 3$ suggested that tyrosine is essential at position 143. Her phenotype strongly resembled that of the socalled KO variant with an Arg-Thr insertion between 160 and 161 of $\alpha \mathrm{IIb}$ (Figure 1). Notwithstanding, cells transfected with $\alpha \mathrm{IIbH} 143 \beta 3$ underwent a partial clot retraction, whereas the $\mathrm{KO}$ variant abrogated it.

\section{Variant Forms of GT and $\alpha \mathrm{llb} \beta 3$ Functioning}

Activation of $\alpha \mathrm{IIb} \beta 3$ by "inside-out" signaling involves conformational changes in the subunit tails that when transmitted to the extracellular domains enable ligand binding. ${ }^{8}$ This and/or clustering of $\alpha \mathrm{IIb} \beta 3$ initiate "outside-in" signaling and responses such as platelet spreading on $\mathrm{Fg}$ and clot retraction where $\alpha \mathrm{IIb} \beta 3$ transmits forces generated by actin and myosin. Important is 
phosphorylation of the $\beta 3$-cytoplasmic tail and c-Src and RhoA activities with retraction regulated by a molecular switch involving $\beta 3$ dephosphorylation and cleavage at Y759. ${ }^{53}$ Variants that mostly possess $50 \%$ or more $\alpha \operatorname{IIb} \beta 3$ in their platelets show loss of function and may concern one or both signaling pathways.

\section{Mutations Affecting Extracellular Domains}

Loss-of-function mutations that block the ability of $\alpha \operatorname{IIb} \beta 3$ to bind Fg when stimulated (Figure 1) have largely contributed to our understanding of how ligand binding occurs. The CAM variant was the first genotyped GT variant, a homozygous p.D119Y substitution causing loss of a divalent cation structured Fg-binding site within the MIDAS domain of $\beta 3 .{ }^{54}$ Also of major importance were homozygous p.R214Q or $\mathrm{W}$ substitutions within the ADMIDAS (adjacent to MIDAS) domain of $\beta 3 .^{55,56}$ Here, $\alpha \operatorname{Ilb} \beta 3$ was hypersensitive to divalent cation chelation and unable to bind Fg. In all cases, clot retraction and the platelet Fg storage pool were severely reduced. Yet treatment of $\alpha \mathrm{IIb} \beta 3$ with dithiothreitol restored the Fgbinding capacity. These extracellular variant forms occurred in patients with clinically severe GT. While mostly the mutations affect $\beta 3$, the Japanese KO variant (also associated with severe bleeding) is an exception. ${ }^{57}$ Here, platelets fully expressed $\alpha \operatorname{IIb} \beta 3$ that is unable to bind Fg or PAC-1 when stimulated and clot retraction is subnormal. In addition, $\alpha \operatorname{IIb} \beta 3$ was refractory to the activating MoAb PT25. A homozygous p.R,T160-161 insert on the upper face of the $\alpha \mathrm{IIb} \beta$-propeller localized to the C146-C167 loop; a purported ligand-binding site. Alanine substitution of oxygenated residues within this loop and expression in 293 cells revealed that only D163A abolished ligand-binding function.

\section{Cytoplasmic Domain Mutations}

Platelets of an elderly Argentinian man with a mild bleeding syndrome failed to bind $\mathrm{Fg}$ or aggregate with ADP despite $44 \%$ of normal levels of $\alpha \operatorname{IIb} \beta 3 .{ }^{58}$ Uniquely, he experienced severe limb deep vein thrombosis (DVT) after a long air flight. ${ }^{3,19}$ His $\alpha$ IIb $\beta 3$ was predominantly in an internal platelet pool. Possessing a heterozygous $\beta 3 \mathrm{p}$. S752P cytoplasmic domain mutation his platelet Fg and clot retraction were near normal. While platelet aggregation and soluble Fg-binding remained minimal, $\alpha$-granule Fg was secreted attached to $\alpha \operatorname{IIb} \beta 3$ of internal membranes after platelets were challenged with thrombin. ${ }^{59}$ An RGDS-affinity column retained detergent solubilized $\alpha \operatorname{Ilb} \beta 3$ from his platelets confirming an intrinsic Fgbinding capacity. ${ }^{58}$ As his daughter's platelets aggregated normally while retaining $50 \% \alpha \operatorname{IIb} \beta 3$ expression, the father was hypothesized to have a "nul" allele. A key to the effect of this mutation is loss of binding of kindlin-3, an essential protein for $\alpha \operatorname{Ilb} \beta 3$ activation. ${ }^{8,15} \mathrm{~A}$ similar phenotype in a black American girl with severe bleeding and platelets expressing intermediate levels of nonfunctional $\alpha \operatorname{Ilb} \beta 3$ was given by compound heterozygosity associating a null allele and a c.2268C $>$ T, p.R724* variant giving a truncated protein missing the final 39 amino acids of the $\beta 3$ cytoplasmic domain. ${ }^{60}$ This patient lacked not only the kindlin-3 binding site but also a talin-binding domain essential for $\alpha \mathrm{IIb} \beta 3$ signaling. ${ }^{61} \mathrm{CHO}$ cells expressing $\alpha \operatorname{IIb} \beta 3 \mathrm{R} 724 *$ failed to spread on Fg associated with a loss of FAK phosphorylation.

\section{Extracellular Activating Mutations in allb $\beta 3$}

Activating mutations within extracellular domains mostly concern cysteine residues, and $\beta 3$ is rich in conserved disulfides of which 31 localize to the EGF domains. Pionering was a homozygous p.C560R substitution in the B3 EGF-3 domain of a Frenchman whose platelets expressed 20\% $\alpha \mathrm{IIb} \beta 3$ (Figure 1). ${ }^{62} \mathrm{He}$ had a mild form of GT despite a long bleeding time and mild thrombocytopenia $\left(100\right.$ to $150 \times 10^{9}$ platelets/L). Although platelet anisotropy was noted, platelet size changes were not striking. The patient underwent a kidney transplant when middle-aged and required multiple transfusions. The residual integrin on his platelets spontaneously bound anti-LIBS MoAbs and PAC-1. Strikingly, his circulating platelets had significant amounts of surface-bound $\mathrm{Fg}$ organized in clusters. ${ }^{62}$ Yet his platelets showed no visual signs of being activated and secreted normally with thrombin when a delayed but residual platelet aggregation occurred. Clot retraction was severely reduced, but platelet $\mathrm{Fg}$ was normal. A stable CHO cell line expressing $\alpha \mathrm{IIb} \beta 3 \mathrm{R} 560$ mimicked the properties of the patient's platelets, and spontaneously bound PAC- 1 . The cells attached readily to surface-bound Fg spreading with increased velocity. Interestingly, the patient died when elderly from a thrombotic event. Mor-Cohen et $\mathrm{al}^{63}$ identified a founder p.C549R variant in $\beta 3$ in consanguineous Jordanian Arab families with type II GT and severe 
bleeding. Platelet aggregation was markedly impaired and clot retraction reduced. Transfected BHK cells showed that surface $\alpha \operatorname{IIb} \beta 3$ spontaneously and maximally bound PAC-1, while WB showed a higher than normal presence of pro- $\alpha \mathrm{IIb}$ much of which was retained in the ER. The affected C549 forms a highly conserved disulfide with C558 in EGF-3. Kamata et $\mathrm{al}^{64}$ investigated the role of $\beta 3$ disulfides by systematically substituting cysteine with serine followed by the expression of the recombinant $\alpha \mathrm{IIb} \beta 3$ in $\mathrm{CHO}$ cells. Disruption of a single disulfide in the EGF domains commonly led to activated integrin, while disruption of only 2 of 13 disulfides outside this region led to activation.

But not all activating mutations involve cysteine residues (Figure 1). An intriguing patient was reported by Vanhoorelbeke et $\mathrm{al}^{65}$ and involved a heterozygous $\mathrm{p}$. S527F substitution in the I-EGF-3 domain of $\beta 3$. The proband was a young Arab man with mild bleeding and much decreased platelet aggregation with ADP despite normal $\alpha \operatorname{IIb} \beta 3$ numbers. Most studies were performed using transfected CHO cells with the mutated integrin spontaneously binding Fg and PAC-1. Intriguingly, the cells formed aggregates when stirred with Fg. Anti-LIBS MoAbs bound spontaneously to $\alpha \mathrm{IIb} \beta 3 \mathrm{~F} 527$ although their binding increased when RGDS was present. $\beta 3$ F527 probably causes steric hindrance preventing the I-EGF-3 domain from entering a cleft necessary for the bent integrin resting conformation. A 6-month-old girl with mucocutaneous bleeding had platelets unable to aggregate or retract a clot although platelet $\mathrm{Fg}$ was present. ${ }^{66}$ Amounts of $\alpha \mathrm{IIb}$ and $\beta 3$ were substantial although estimated as below 50\%. ADP stimulated platelets failed to bind PAC-1 but strangely some Fg binding was noted. Sequencing revealed compound heterozygosity for $\mathrm{p}$. D119Y and p.M124V missense mutations within the $\beta 3$ MIDAS domain. Homozygous p.D119Y gives rise to the classic CAM variant (see the preceding section). ${ }^{54} \mathrm{CHO}$ cells transfected with $\alpha \mathrm{IIb}$ and $\beta 3 \mathrm{~V} 124$ showed increased adhesion and spreading on immobilized Fg despite a low surface expression of the mutated integrin. They also formed aggregates when agitated with soluble Fg, suggesting that $\alpha \operatorname{IIb} \beta 3 \mathrm{~V} 124$ was constitutively active. The failure of the patient's platelets to spontaneously aggregate was probably due to the dominance of the loss-of-function $\alpha \operatorname{IIb} \beta 3$ Y 119. About $50 \%$ of the recombinant $\alpha \mathrm{IIb} \beta 3 \mathrm{~V} 124$ was present as pro- $\alpha \mathrm{IIb} \beta 3$ in the transfected cells showing a delayed maturation.

Questions are raised as to why the platelets of patients with activating mutations do not obstruct the microcirculation. One possibility is that the Fg binds monovalently and thereby blocks platelet-to-platelet cohesion.

\section{Macrothrombocytopenia (MTP) and a GT-Like State}

The cases in the earlier section possess gain-of-function mutations with AR inheritance but without significant abnormalities in platelet count and size. In contrast, an increasingly noted group of patients associate single allele gain-of-function variants of $\alpha \mathrm{IIb} \beta 3$ with $\mathrm{AD}$ transmission and MTP (Table 1) (Figure 1). In the early 1990s, my colleagues and I reported an unique case with mild bleeding, mild thrombocytopenia (100-160 × $\left.10^{9} / \mathrm{L}\right)$, some enlarged platelets and defective platelet aggregation. ${ }^{67,68}$ Although surface $\alpha \mathrm{IIb} \beta 3$ was $10-20 \%$ of normal, his platelets mediated clot retraction and stored $\mathrm{Fg}$; a normal $\alpha \mathrm{IIb} \beta 3$ internal pool suggested defective recycling to the surface. Mutation screening first highlighted a heterozygous p.R995Q mutation within the highly conserved GFFKR sequence of the $\alpha \mathrm{IIb}$ cytoplasmic tail. Expression of $\alpha \mathrm{IIbQ995} \beta 3$ in Cos-7 and CHO cells confirmed a reduced transport to the cell surface. Although the mutated $\alpha \mathrm{IIb} \beta 3$ did not bind Fg spontaneously, there was weak binding of PAC-1. Significantly, $\alpha$ IIbR995 forms an intracellular salt bridge with $\beta 3 \mathrm{D} 723$ and weakening or breaking this link upgrades the activation status of $\alpha \operatorname{IIb} \beta 3$ (Figure 1). ${ }^{69}$ Family studies showed that R995Q came from his father, but discrepancies in their $\alpha \operatorname{IIb} \beta 3$ expression predicted a non-identified second maternal mutation in the son. This was later identified as a pathogenic $13 \mathrm{bp}$ intronic deletion near the splicing acceptor site for exon 15 of $I T G A 2 B$ (its mechanism is discussed later in the review). ${ }^{17}$ Subsequently, patients in five Japanese families with MTP and AD inheritance were reported with a heterozygous p.R995W substitution. ${ }^{70}$ With a normal second allele platelet surface $\alpha \operatorname{IIb} \beta 3$ expression was $50 \%$ to $70 \%$ of normal. Spontaneous PAC-1 binding to platelets or transfected $293 \mathrm{~T}$ cells confirmed that $\alpha \mathrm{IIb} \beta 3$ was in a partially activated conformation. Furthermore, when they were plated on Fg they spontaneously formed proplatelet-like protrusions - a finding previously reported for a patient with a heterozygous $\beta 3$ p.D723H variant, D723 being the partner for R995 in the salt bridge linking the two cytoplasmic domains. ${ }^{70,71}$ However, enigmatically this latter patient while having MTP did not have a significant platelet aggregation defect. Later, three 
French families were reported with MTP, GT-like defects and heterozygous variants affecting the salt bridge. ${ }^{72}$ Two families possessed p.R995W in $\alpha \mathrm{IIb}$ and the third p. $\mathrm{D} 723 \mathrm{H}$ in $\beta 3$. In silico modeling confirmed that both variants created steric interference, weakening the intracytoplasmic ionic clasp but with secondary influences extending to other nearby amino acids. For all the above patients both the bleeding syndrome and the MTP were moderate. Nevertheless, their phenotypic variability was striking. Platelet $\alpha \operatorname{IIb} \beta 3$ expression ranged from $25 \%$ to $50 \%$. Intriguingly, electron microscopy showed many enlarged round platelets often with a heterogeneous distribution of $\alpha$-granules many of which showed signs of fusion. Early MK maturation was normal, but proplatelets were short and had enlarged tips. Recently, Morais et al ${ }^{73}$ have reported more European cases with $\mathrm{AD}$ variants affecting the salt bridge and all with mild forms of MTP; again the authors emphasized the phenotypic variability of such cases and which extended to the degree of spontaneous activation of $\alpha \operatorname{Ilb} \beta 3$.

Mutations in the single-pass transmembrane domains of $\alpha \operatorname{Ilb} \beta 3$ can also give MTP. Members of two Italian families associated a moderate $\mathrm{AD}$ thrombocytopenia with large platelets, defective platelet function and moderate/severe bleeding. ${ }^{74}$ The platelets associated a low surface $\alpha \operatorname{IIb} \beta 3$ expression with minimal spontaneous PAC-1 binding. Platelet spreading on Fg was impaired as was shear-dependent platelet adhesion to collagen. Yet clot retraction was normal. A novel heterozygous mutation in $I T G B 3$ led to a large in-frame deletion (p.D621-E660). Truncated $\beta 3$ was noted in their platelets and a dominant negative effect was hypothesized. A heterozygous $\mathrm{p}$. L718P mutation in $\beta 3$ was reported in a Spanish woman with severe bleeding and MTP. ${ }^{75}$ Platelet aggregation was much reduced and a secretion defect was found with little surface expression of P-selectin and CD63. Surface $\alpha \operatorname{Ilb} \beta 3$ was selectively reduced. Her platelets spread poorly on $\mathrm{Fg}$ with defective lamellipodia. $\mathrm{CHO}$ cells expressing recombinant $\alpha \mathrm{IIb} \beta 3 \mathrm{P} 718$ directly bound Fg and PAC-1 and spontaneously agglutinated in the presence of Fg. When plated on Fg, they formed long extensions often with a swelling at the tip. We have reported a heterozygous $\beta 3$ p.L718del in a woman with a GT-like syndrome with MTP; her platelets did not spontaneously bind PAC-1. ${ }^{76}$ Platelet anisotropy was again associated with enlarged "fused" $\alpha$-granules. Recently, Morais et $\mathrm{al}^{73}$ have added p.G976V in allb and p.T720P, p.H722P and p.R734H (p.
$\mathrm{R} 760 \mathrm{H})$ in $\beta 3$ to the list causing MTP with GT-like functional defects (Figure 1).

These patients raise important questions. Quite clearly, the conformational status of $\alpha \operatorname{IIb} \beta 3$ influences MK reactivity with extracellular proteins in the bone marrow and affects platelet biogenesis, but the relationships between the changes caused by the above mutations and the step-by -step exposure of the determinants that allow soluble $\mathrm{Fg}$ binding remain to be determined. Furthermore, an argument can be made that "Glanzmann thrombasthenia-like macrothrombocytopenia" should define a distinct disease in the way that "platelet-like VWD" has common usage to define upregulated binding of VWF to GPIb. ${ }^{77,78}$

\section{Large Series and Frequency of GT Subtypes}

As sequencing capacity progressed, large cohorts of GT patients were genotyped and have considerably extended our insight into the mutation repertoire of this disease. Initially, Peretz et $\mathrm{al}^{79}$ examined the molecular basis for GT in 40 families with a high degree of parental consanguinity from Southern India. Most patients had type I GT and 23 mutations (13 in ITGA2B and 10 in ITGB3) were identified. Founder effects were confirmed by haplotyping families with repeated p.L117W and p.Y281* mutations reflecting the closeness of the communities. Subgroups were not identified although a $\beta 3$ p.R67Q variant had normal $\alpha \operatorname{IIb} \beta 3$ expression and clot retraction. Missense mutations affecting $\alpha \mathrm{IIb}$ primarily concerned the $\beta$ propeller or thigh domains while those in $\beta 3$ were distributed within the PSI, $\beta$-I and hybrid domains. Nelson et $\mathrm{al}^{80}$ followed with a further 15 patients from the same communities. Significantly, 14 showed no $\alpha$ IIb in WB and 10 had no $\beta 3$, while for 4 others, $\beta 3$ was severely reduced. Platelet Fg was undetectable for 13 patients, severely reduced in 1; only 1 patient had normal platelet surface $\alpha I I b \beta 3$ expression and normal Fg. Disease-causing mutations were identified for 11 patients with type I GT predominating.

Jallu et $\mathrm{al}^{81}$ examined phenotype/genotype relationships in 24 Paris patients with 19 classed as type I and 3 as type II. They identified 29 mutations, their validation included expression in COS-7 cells, in silico analysis and mRNA processing. Noteworthy was a p.Q595H substitution that failed to change $\alpha \operatorname{IIb} \beta 3$ expression in COS-7 cells despite its absence from platelets; in fact, the causal c. $1878 \mathrm{G}>\mathrm{T}$ transversion led to altered mRNA splicing 
and skipping of exon 18 in megakaryocytes. One type II patient was compound heterozygous for an ITGA2B c.3060+2T $>C$ transition leading to deletion of exon 29 . For another, only a heterozygous ITGA2B p.R946* nonsense mutation was detected with a predicted but nonidentified second allele mutation allowing residual expression of $\alpha \operatorname{IIb} \beta 3$. Two type II patients had platelets with substantial pools of $\mathrm{Fg}$ ( $51 \%$ and $83 \%$, respectively,). Sandrock-Lang et al ${ }^{82}$ in Germany reported 19 GT patients including 11 type I and 2 type II. They found 27 mutations. One type II patient, a male Arab with severe bleeding, was compound heterozygous for the ITGA2B p.L183P missense mutation and a c.3092delT within exon 30 of $I T G A 2 B$ introducing a Fs and a protein prolonged in the cytoplasmic tail. The second patient combined a p.I154M missense mutation and a known p.R597X stop codon within ITGA2B. Both missense mutations affected the $\alpha \mathrm{IIb} \beta$-propeller.

In Bordeaux, we led a large international consortium that genotyped members of 76 affected families. ${ }^{17}$ Sequencing in a national sequencing center (Genoscope) identified 78 disease-causing variants; in parallel 4 large deletions or duplications were found using quantitative real-time PCR. Most families were from France; others were from Argentina, Canada, Morocco, Spain, Switzerland and the USA. Many had a history of blood transfusions or rFVIIa in response to bleeding or preventively. Occasionally bleeding was mild and wide variability was highlighted. Phenotyping assigned 58 families with type I GT, 9 with type II and 8 had variant forms. ITGA2B missense mutations mainly affected the $\beta$-propeller and caused type I GT but gave type II in three families. Of the calf-1 and calf-2 domain mutations, p.V903F reoccurred in two nonrelated French families with type II GT and compound heterozygosity; expression studies confirmed an altered maturation of pro- $\alpha \mathrm{IIbF} 903 \beta 3$. An elderly French male with type II GT associated an ITGA2B p.G792E missense variant with a stop codon. Heterozygous p.C674R associated with a null allele in a patient with type II GT was first reported with homogeneous expression in Spanish patients with type II GT (Suppl Table I). ${ }^{32}$ Noteworthy were missense p.Q595H and p.F160V mutations given by nucleotide transitions that also interfere with splicing as previously noted for $\mathrm{p}$. Q595H by Jallu et al. ${ }^{81}$ While homozygous $\beta 3$ mutations mostly gave type I GT, a heterozygous p.R37C variant associated with p.R143* in a patient with type II GT. When expressed in COS-7 cells, intracellular pro- $\alpha \operatorname{IIb} \beta 3 \mathrm{C} 37$ predominated. While most $\beta$-I domain mutations gave type I GT, the type II subgroup was occasionally seen. Four missense mutations localized to the disulfide-rich $\beta 3$ EGF-3 and EGF-4 domains but gave type I GT. Multiple stop codons and splice site variations affected both genes. Particularly interesting was a French patient heterozygous for the Manouche gypsy mutation with $50 \% \alpha$ IIb $\beta 3$ but no platelet aggregation and who was also homozygous for a FERMT3 mutation. ${ }^{83}$ FERMT3 encodes kindlin-3 and its absence rendered the residual $\alpha \operatorname{IIb} \beta 3$ non-functional. Clinically, his severe bleeding phenotype was associated with mild immunodeficiency characteristic of leukocyte adhesion deficiency type III (LAD-III) syndrome given by mutations of FERMT3. A Jamaican patient with normal $\alpha \operatorname{IIb} \beta 3$ and no mutations in $I T G A 2 B$ and $I T G B 3$ was later found by my group to be homozygous for a mutation in RASGRP2 abrogating CaLDAG-GEFI function. ${ }^{84}$ Careful phenotyping is needed to exclude RASGRP2 and FERMT3 defects in cases with variant GT (Table 1).

Exon skipping occurred in three families with ITGA2B variants and in five families with ITGB3 variants. Enigmatic was a heterozygous 13-bp single allele deletion in intron 14 first reported by Jallu et $\mathrm{al}^{81}$ and affecting seven families with type I GT and no obvious ancestral links. These included three Catalan family members confirming its inheritance. A hybrid minigene transfection assay in COS-7 cells showed that it invoked a new cryptic $5^{\prime}$ splice site causing a 2-bp deletion in the mRNA, a reading-frame shift, and a premature stop codon after 105 aberrant amino acids. The abnormal mRNA was also predicted to be a target for nonsense-mediated decay.

\section{GT Platelets and Fibrin}

While early studies confirmed a role for $\alpha$ IIb $\beta 3$ in fibrindependent clot retraction, the wide diversity in the mutationdependent responses in type II and variant GT imply that Fg and fibrin interact with different sites on $\alpha \operatorname{IIb} \beta 3$. Podolnikova et $\mathrm{al}^{85}$ showed how a cluster of newly exposed amino acids in the Fg $\gamma 370-381$ sequence mediate the interaction of immobilised Fg or fibrin with $\alpha \mathrm{IIb} \beta 3$. Much later, the same group revealed how this cluster had several potential contact sites within the $\alpha$ IIb $\beta$-propeller. ${ }^{86}$ These differ from the activation-dependent sites on $\alpha \operatorname{IIb} \beta 3$ that mediate binding of the $\gamma 404$ GAKQAGDV411 peptide or RGDS sequences of $\mathrm{Fg}$ and which respectively localize to the extremity of the $\alpha \mathrm{IIb} \beta$-propeller and to the $\beta 3 \beta-\mathrm{I}$ domain. ${ }^{8,35}$ The situation clarified when the GPVI collagen 
receptor on platelets was also shown to recognize fibrin and surface-bound Fg. ${ }^{87,88}$ Thus, not only does GPVI participate in platelet binding to the vessel wall, it also intervenes as a more generalized signaling receptor in thrombus formation. GPVI not only may explain the accumulation of platelets of type I GT patients on fibrin, it may also intervene in the microthrombus formation seen for some patients. Nonetheless, the genetic absence of GPVI does not abrogate clot retraction and recent studies show that GPVI and $\alpha \operatorname{IIb} \beta 3$ play complementary non-redundant roles. ${ }^{89,90}$ GPVI may also have a physiologic role in inflammatory states, cancer and other acquired states in GT. ${ }^{19,91}$

\section{Platelet Proteome}

Some 40 years ago, McGregor et $\mathrm{al}^{92}$ studied platelet membrane glycoproteins in GT by associating carbohydrate-specific or protein-specific labeling procedures with high-resolution two-dimensional gel electrophoresis. Glycosylation defects of residual GPIIb and GPIIIa extended to other components of the platelet surface in type I and type II GT; suggesting an unexplored source of functional heterogeneity. Loroch et $\mathrm{al}^{93}$ investigated platelet function and the platelet proteome in type I GT patients with homozygous Fs mutations in ITGA2B leading to premature stop codons. Mass spectroscopy validated about 3\% $\alpha \mathrm{IIb}$ and $5 \% \beta 3$ in platelets of the two patients studied. Signaling proteins such as kindlin-3, CalDAGGEFI, and Src were all normally present as were $\alpha v$, GPIbIX and GPVI. Downregulated in platelets were Fg, FXIIIB, carboxypeptidase-B2 (a fibrinolysis inhibitor) and plasminogen despite normal plasma levels. Fc $\gamma$ RIIA and laminin- $\alpha 4$ were upregulated. Megakaryocytes synthesize FXIIIA that is stored in platelets but FXIIIB is taken up - perhaps in association with Fg. Plasminogen interacts with carboxypeptidase B suggesting a common endocytic pathway. Fc $\gamma$ RIIA increase was linked to increased dense granule secretion in response to immunoglobulin complexes. Recently, Blair et al $^{94}$ used state-of-the-art mass spectrometry (MS) and metal-tagged antibodies to study activation-dependent changes on GT platelets. They highlighted the elevated levels of CD9, CD42a and CD63 while the density of CD21, CD154 and GPVI was low. CD9 and CD63 are granule markers that were increased, whereas the normal expression of $\mathrm{P}$-selectin, another granule membrane protein, was unexplained. But perhaps more significant is that the bulk of the platelet proteome appeared to be unchanged. It would be interesting to examine a wider range of patients including variant forms.

\section{Diagnosis and High-Throughput Sequencing}

The advent of high-throughput sequencing (HTS) for diagnosis of IPDs has greatly accelerated gene identification and mutation analysis as well as posing new sets of challenges. ${ }^{77,78,95,96}$ Precise genotyping in GT is required for optimal clinical management. It also provides insight into $\alpha \operatorname{IIb} \beta 3$ structure-function relationships, facilitates family planning and assists in the development of new treatments including gene therapy. Targeted sequencing (TS), whole-exome sequencing (WES) or whole-genome sequencing (WGS) are all viable options with TS against a selected gene panel including ITGA2B and ITGB3 the initial and most economic choice for GT. Potential users should consult the annually updated curated gene panel from the ISTH SSC. ${ }^{95}$ The gene panel should also include RASGRP 2 encoding CaLDAG-GEFI and FERMT3 encoding kindlin-3 whenever the clinical profile suggests GT variant-like platelet function. While WES can cover intronic flanking regions and splice sites its basic advantage is to allow the detection of new genes. A negative result in TS and WES should be followed by WGS when possible, but both WES and WGS require extensive computer-based facilities and technical back up. ${ }^{96}$ Key is the classification of variants into those with known pathogenicity, likely pathogenic and those with uncertain pathogenicity, while copy number variations represent a separate challenge as do variants deep within introns (reviewed in Ver Donck et $\mathrm{al}^{96}$ ). Particularly interesting is that for some patients bleeding results from combinations of homozygous or single allele mutations on two or more different genes that may or may not involve ITGB3 or ITGA2B. Variant analysis should also include those of modest pathogenicity that on their own do not cause a sufficient inhibition of platelet function to disturb hemostasis but which may nonetheless modulate disease severity. The identification of gene modifiers that influence disease pathogenesis and penetrance in GT is a major future challenge.

\section{Extent That Mutations of ITGA2B and ITGB3 are Found in the General Population}

In a pioneering study, Buitrago et $\mathrm{al}^{97}$ analysed nextgeneration sequencing data (WES and WGS strategies) from five international databases and assessed the frequency of missense mutations affecting $\alpha \mathrm{IIb}$ and $\beta 3$ in 16,108 normal individuals and compared their findings to 
111 missense mutations reported in the literature as causing GT. Their survey identified 114 missense variants in $I T G A 2 B$ (affecting $11 \%$ of the amino acids) and 68 in ITGB3 (affecting $9 \%$ of the amino acids). Of these, $96 \%$ had minor allele frequencies (MAF) of $<0.1 \%$ while a significant proportion were predicted to be deleterious. Strikingly, none of the missense mutations known to cause GT were present. This study showed that $1.3 \%$ of the population has a variant of ITGA2B or ITGB3. The authors concluded that on the basis of their rarity, the bulk of the amino acid substitutions had entered the population recently. We hypothesized that if this applied to the GTcausing mutations in our international cohort, then many patients would share non-damaging synonymous and nonsynonymous SNPs in both genes. ${ }^{17,98}$ We therefore quantified non-disease causing genetic variants including human platelet alloantigen (HPA) polymorphisms within the sequenced regions of ITGA2B and ITGB3. ${ }^{98}$ Our results show that many damaging and GT-causing mutations share SNP haplotypes with little genetic variation in unrelated families of wide geographical origins: a result that agrees with many GT-causing mutations being of recent origin. It is probable that a high proportion of private mutations outside ethnic groups and closed communities will disappear due to natural selection and that the mutation profile in GT is constantly changing.

\section{Treatment}

If local measures fail, GT patients receive platelet transfusions or recombinant factor VIIa (rFVIIa) given with or without anti-fibrinolytics. George et $\mathrm{al}^{3}$ evaluated treatment for 112 patients followed in Paris and reported that a majority had received such measures at least once. However, the extent of bleeding was difficult to predict and had no dependence on whether the patient had type I, type II or variant GT. This has been confirmed many times; bleeding may vary considerably in severity and frequency even among members of the same family. ${ }^{17,26}$ One situation where treatment is adapted is in the presence of isoantibodies to $\alpha \mathrm{IIb} \beta 3$ with rFVIIa advised for patients with inhibitors and refractoriness. ${ }^{99,100}$ Occasional adverse events linked to rFVIIa have mostly involved DVT. ${ }^{19} \mathrm{Al}-$ Battat et $\mathrm{al}^{101}$ showed that platelets from type I patients compete with and hinder the hemostatic efficacity of transfused platelets and emphasized the importance of maintaining a high proportion of transfused platelets. But the major risk of platelet transfusion remains immune sensitization when the integrin is lacking in type I GT. ${ }^{102,103}$ In this respect, genotyping and biological testing helps choice of treatment.

Pregnancy is rare in women with type I GT both through individual choice and the long-term use of hormonal therapy. Apart from bleeding risk, pregnancy may lead to immunization following passage of fetal cells into the mother's circulation. ${ }^{103}$ Transplacental passage of maternal antibodies may cause thrombocytopenia in the fetus. Leticée et al $^{104}$ described pregnancy in a woman with type I GT and isoantibodies following blood transfusions. As the husband's platelets fully expressed $\alpha \mathrm{IIb} \beta 3$, the fetus was an obligate heterozygote. Fetal death occurred at 31 weeks due to intracranial hemorrhage. Although absent from platelets when $\alpha \operatorname{IIb} \beta 3$ and $\alpha v \beta 3$ are lacking, HPA-systems on $\beta 3$ are a factor on platelets and other cells that express $\alpha v \beta 3$ when the gene defects affect ITGA2B as well as in type II GT and for variant GT. The risk of antibody formation will remain in the event of alloantigen incompatibility. Santoso et al ${ }^{105}$ found that intracranial hemorrhage in mothers with fetal/ neonatal alloimmune thrombocytopenia (FNAIT) caused by anti-HPA-1a antibodies, was predominately due to their reactivity with $\alpha v \beta 3$ in endothelial cells. Evidence for anti-HPA-1 alloantibodies reactive with $\alpha v \beta 3$ in GT was provided by Fiore et al $^{106}$ who detected them in polytransfused patients with the French Manouche gypsy mutation (on $I T G A 2 B$ ) with $\alpha v \beta 3$ in platelets and other cells expressing $\beta 3$ homozygous for the rare HPA$1 \mathrm{~b}$ allele. Thus HPA typing is recommended in GT and especially for affected women.

\section{How Other Gene Defects Can Modify the GT Phenotype}

High-throughput gene screening allows the simultaneous evaluation of a wide variety of gene variants that can influence the GT phenotype. In addition to the examples already illustrated in this review and in the literature for other IPDs, ${ }^{96}$ it allowed us to find a heterozygous p.G146R mutation in $T U B B 1$ encoding $\beta$-tubulin in a patient who combined MTP and type I GT caused by compound heterozygosity of p.P189S and p.C210S in ITGB3. ${ }^{107}$ It is becoming more and more clear that bleeding in GT depends not only on the mutations that define the pathology but involves variants of a wide variety of genes involving coagulation factors and the vasculature as previously discussed for other IPDs. ${ }^{77,78}$ For example, Deshpande et $\mathrm{al}^{108}$ identified a combination of GT and 
mild FVII deficiency in a 13-yr-old Indian boy with GT and a moderately severe bleeding syndrome. His platelets lacked $\alpha \operatorname{IIb} \beta 3$ due to compound heterozygosity for $p$. Q132K and p.K650T in ITGB3. Three polymorphisms (two in the promoter region) of $F 7$ were predicted to cause the FVII deficiency. In a pioneering study, Owaidah et $\mathrm{al}^{109}$ performed targeted sequencing of 72 family members of GT patients in Saudi Arabia and as well as identifying 17 mutations within $I T G A 2 B$ and $I T G B 3$ they found possible disease-influencing variants in ITGA2, VWF and F8. Notwithstanding, the genes analyzed should also include variants potentially protectrice against severe bleeding such as Factor V Leiden but for which the jury is out at the moment with regard to their influence in GT. ${ }^{19,95}$

\section{Human Stem Cell Transplants (HSCT) and Gene Therapy}

Restoring hemostasis in GT patients with life-threatening bleeding by HSCT has proved remarkably successful. Pioneering studies were performed in Paris, first on a brother and later on his sister with severe type I GT and antibodies to $\alpha I I b \beta 3$ making them refractory to transfusions. ${ }^{110}$ Both received bone marrow transplants (BMT) from an asymptomatic sibling but under evolving conditions. Platelet function and $\alpha \operatorname{IIb} \beta 3$ expression was restored and remained stable for years. Significantly antibodies to $\alpha \operatorname{Ilb} \beta 3$ were no longer present. Flood et $\mathrm{al}^{111}$ performed BMT on three type I patients with severe bleeding. Two donors were matched family members but the third was unrelated. A conditioning regimen consisting of busulfan, cyclophosphamide and fludarabine met with isolated episodes of graft versus host disease (GVHD); thrombocytopenia due to antibodies to $\alpha \operatorname{IIb} \beta 3$ was successfully treated by immunosuppressive therapy and intravenous gammaglobulin (IVIgG). Complete and long-term donor engraftment was observed. Poon et $\mathrm{al}^{100}$ reviewed data from an international registry for BMTs in GT composed of 43 patients. Despite variable conditioning regimes and donor graft sources, there was an $81 \%$ survival at a median 47 months. Clearly, HSCT can restore the quality of life in GT; notwithstanding, it remains a last resort due to the possible complications and especially GVHD. The future for treating GT patients with severe bleeding remains gene therapy, yet remarkably this remains at an experimental stage. David Wilcox et al in Milwaukee have been pioneers. First, they transduced BM cells using a lentivirus vector containing a cDNA cassette encoding human $\beta 3$ and transplanted them into irradiated $\beta 3-/-$ mice. ${ }^{112}$ Human $\beta 3$ complexed with murine $\alpha$ IIb but platelets in the mice only expressed around $12 \%$ of the normal levels of functional $\alpha \operatorname{IIb} \beta 3$. Notwithstanding their platelet Fg normalized and their tail bleeding times improved. Antibodies to $\alpha \operatorname{Ilb} \beta 3$ were observed in one mouse, but perfusion of IVIgG slowed platelet clearance. Studies followed on dogs with an ITGA2B mutation and type I GT. ${ }^{113}$ Bleeding was corrected, but the expression of chimeric $\alpha \operatorname{IIb} \beta 3$ in the platelets again remained low with only about $10 \%$ platelets expressing around 5000 copies of $\alpha \operatorname{IIb} \beta 3$. One of four dogs formed antibodies to $\alpha \operatorname{IIb} \beta 3$ that were eliminated by IVIgG. However, questions are raised as platelets of patients with type II GT and uniformly expressing $10 \%$ of functional $\alpha \mathrm{IIb} \beta 3$ can have a serious bleeding syndrome. Clearly improved protocols are required. Two alternative procedures are promising. The first is the use of patient-derived induced pluripotent stem cells (iPSCs). Sullivan et $\mathrm{al}^{114}$ designed a specific construct to reprogram monocytes from two patients with type I GT to produce iPSCs with restored synthesis of $\alpha \operatorname{IIb} \beta 3$. Their procedure led to corrected $\alpha \operatorname{IIb} \beta 3$ expression and function in MKs. Hu et $\mathrm{al}^{115}$ generated iPSCs from skin fibroblasts from a boy with type I GT and compound heterozygosity in ITGA2B. Differentiation of the iPSCs into MKs and restoration of the defective gene led to platelets expressing $\alpha \mathrm{IIb} \beta 3$; nonetheless, the difficulties encountered led the authors to suggest that blood cells were a better source for iPSCs. Notwithstanding, CRISPR/Cas technology has opened new concepts for directly correcting gene defects in rare diseases and GT will be an obvious choice. As proof of concept, Zhang et $\mathrm{al}^{116}$ edited the genome of heterologous cells and then iPScs to change HPAs. More precisely, iPSCs expressing HPA-1a ( $\beta 3$ Leu33) were converted to HPA-1b ( $\beta 3$ Pro33) and then differentiated into progenitor cells. The advantage of CRISPR/Cas procedures is that the correction is made on the patient's own cells; therefore, the question of immune tolerance is of lesser importance. This field offers much scope for future years.

\section{Conclusions}

Looking back over a long career that nears 50 years has enabled me to review the progress made and to offer thoughts for the future. Clearly, an improved point-ofcare test to better evaluate bleeding risk under the flow conditions of the microcirculation is needed as is a spot 
test to allow the rapid detection of antibodies to $\alpha \mathrm{IIb} \beta 3$ prior to surgery or delivery. While the classification of GT patients into type I, type II and variant subgroups has served a useful purpose, genotyping has confirmed that GT as a whole is not divided into subgroups but consists of a range of genetic defects leading to an absence of $\alpha \operatorname{IIb} \beta 3$ or residual amounts that vary in quantity and function with no clear boundaries between them. An international consensus is required to determine if AD GT-like MTP should be given separate status in a similar way to platelet-type VWD. The place of genotyping and the use of high-throughput sequencing procedures will gain in importance and their early use will allow for more rapid and targeted biological testing. Finally and most importantly, while gene mutations define the disease, bleeding severity depends on a range of other factors, both epidemiological and genetic and defining these must be the priority in coming years as personalized medicine and gene therapy become options for patient care. Notwithstanding, differential diagnosis and biological studies will remain an essential part of accurate patient phenotyping and patient management, especially in thirdworld countries. ${ }^{117}$ The place of new technologies both in platelet function testing and in genotyping will need continued and constant evaluation.

\section{Note}

Human Genome Variation Society (HGVS) nomenclature is used throughout for cDNA and protein numbering. For nucleotide numbering, the A nucleotide of the ATG start codon was designated +1 (cDNA ITGA2B and ITGB3 GenBank accession numbers NM_000419.3 and NM_000212.2, respectively). For amino acid numbering +1 corresponds to the initiating Met with signal peptide included. However, as the numbering for the mature protein was used for the crystal structure of $\alpha \mathrm{IIb} \beta 3$ [see Xiao et $\mathrm{al}^{10}$ and Nurden et $\left.\mathrm{al}^{15}\right]$, mature protein numbering is used here for missense and other mutations affecting protein structure. This involves subtracting 31 amino acids from the HGVS numbering of $\alpha \mathrm{IIb}$ and 26 amino acids for $\beta 3$.

\section{Acknowledgments}

The author acknowledges the help of Xavier Pillois for mutation analysis and Figure preparation.

\section{Disclosure}

The author has no disclosures to declare.

\section{References}

1. Caen JP, Castaldi PA, Leclerc JC, et al. Congenital bleeding disorders with long bleeding time and normal platelet count. I. Glanzmann's thrombasthenia (Report of 15 patients). $\mathrm{Am}$ J Med. 1966;41(1):4-26. doi:10.1016/0002-9343(66)90003-9

2. George JN, Caen JP, Nurden AT. Glanzmann thrombasthenia: the spectrum of clinical disease. Blood. 1990;75(7):1383-1395.

3. Bellucci S, Caen J. Molecular basis of Glanzmann's thrombasthenia and current strategies in treatment. Blood Rev. 2002;16 (3):193-202. doi:10.1016/S0268-960X(02)00030-9

4. Nurden AT, Caen JP. An abnormal platelet glycoprotein in three cases of Glanzmann's thrombasthenia. Br J Haematol. 1974;28 (2):233-253. doi:10.1111/j.1365-2141.1974.tb06660.x

5. Phillips DR, Agin PP. Platelet membrane defects in Glanzmann's thrombasthenia. Evidence for decreased amounts of two major glycoproteins. J Clin Invest. 1977;60(3):535-545. doi:10.1172/ JCI108805

6. Hagen I, Nurden A, Bjerrum OJ, Solum NO, Caen J. Immunochemical evidence for protein abnormalities in platelets from patients with Glanzmann's thrombasthenia and BernardSoulier syndrome. $J$ Clin Invest. 1980;65(3):722-731. doi:10.1172/JCI109719

7. Kunicki TJ, Pidard D, Rosa JP, Nurden AT. The formation of Ca2 +-dependent complexes in solution as determined by crossed immunoelectrophoresis. Blood. 1981;58(2):268-278. doi:10.1182/blood.V58.2.268.268

8. Coller BS, Shattil SJ. The GPIIb/IIIa (integrin alphaIIbbeta3) odyssey: a technology-driven saga of a receptor with twists and even a bend. Blood. 2008;112(8):3011-3025. doi:10.1182/blood2008-06-077891

9. Carrell NA, Fitzgerald LA, Steiner B, Ericksen HP, Phillips DR. Structure of human platelet membrane glycoproteins IIb and IIIa as determined by electron microscopy. J Biol Chem. 1985;260 (3):1743-1749. doi:10.1016/S0021-9258(18)89656-9

10. Xiao T, Takagi J, Coller BS, Wang JH, Springer TA. Structural basis for allostery in integrins and binding to fibrinogen-mimetic therapeutics. Nature. 2004;432(7013):59-67.

11. Fitzgerald LA, Steiner B, Rall SC Jr, Lo SS, Phillips DR. Protein sequence of endothelial glycoprotein IIIa derived from a cDNA clone. Identity with platelet glycoprotein IIIa and similarly to "integrin". J Biol Chem. 1987;262(9):3936-3939. doi:10.1016/ S0021-9258(18)61290-6

12. Thornton MA, Poncz M, Korostishevsky M, et al. The human platelet alphaIIb gene is not closely linked to its integrin partner beta3. Blood. 1998;94(6):2039-2047. doi:10.1182/blood. V94.6.2039

13. Newman PJ, Seligsohn U, Lyman S, Coller BS. The molecular genetic basis of Glanzmann thrombasthenia in the Iraqi-Jewish and Arab populations in Israel. Proc Natl Acad Sci USA. 1991;88 (8):3160-3164. doi:10.1073/pnas.88.8.3160

14. French DL, Coller BS. Hematologically important mutations: glanzmann thrombasthenia. Blood Cells Mol Dis. 1997;23 (3):39-51. doi:10.1006/bcmd.1997.0117

15. Nurden AT, Fiore M, Nurden P, Pillois X. Glanzmann thrombasthenia: a review of ITGA2B and ITGB3 defects with emphasis on variants, phenotypic variability, and mouse models. Blood. 2011;118(23):5996-6005. doi:10.1182/blood-2011-07-365635

16. Nurden AT, Pillois X. ITGA2B and ITGB3 gene mutations associated with Glanzmann thrombasthenia. Platelets. 2018;29 (1):98-101. doi:10.1080/09537104.2017.1371291

17. Nurden AT, Pillois X, Fiore M, et al. Expanding the mutation spectrum affecting $\alpha \operatorname{IIb} \beta 3$ integrin in Glanzmann thrombasthenia: screening of the ITGA2B and ITGB3 genes in a large international cohort. Hum Mutat. 2015;36(5):548-561. doi:10.1002/ humu. 22776 
18. Coller BS, Seligsohn U, West SM, Scudder LE, Norton KJ. Platelet fibrinogen and vitronectin in Glanzmann thrombasthenia: evidence consistent with specific roles for glycoprotein $\mathrm{IIb} / \mathrm{IIIa}$ and alphavbeta3 integrins in platelet protein trafficking. Blood. 1991;78(10):2603-2610. doi:10.1182/blood.V78.10.2603.2603

19. Nurden AT. Should studies on Glanzmann thrombasthenia not be telling us more about cardiovascular disease and other major illnesses? Blood Rev. 2017;31(5):287-299. doi:10.1016/j. blre.2017.03.005

20. De Cuyper IM, Meinders M, van de Vijver E, et al. A novel flow cytometry-based platelet aggregation assay. Blood. 2013;121(10): e70-e80. doi:10.1182/blood-2012-06-437723

21. Rodeghiero F, Tosetto A, Abshire T, et al. ISTH/SSC bleeding assessment tool: a standardized questionnaire and a proposal for a new bleeding score for inherited bleeding disorders. J Thromb Haemost. 2010;8(9):2063-2065. doi:10.1111/j.1538-7836.2010.03975.x

22. Schlegel N, Gayet O, Morel-Kopp M-C, et al. The molecular genetic basis of Glanzmann's thrombasthenia I a gypsy population in France: identification of a new mutation on the $\alpha$ IIb gene. Blood. 1995;86(3):977-982. doi:10.1182/blood.V86.3.977.977

23. Kannan M, Ahmad F, Yadav BK, Kumar R, Choudhry VP, Saxena R. Molecular defects in ITGA2B and ITGB3 genes in patients with Glanzmann thrombasthenia. J Thromb Haemost. 2009;7(11):1878-1885. doi:10.1111/j.1538-7836.2009.03579.x

24. Farsinejad A, Farajollahi MM, Kazemi A, Saemi N, Faranoush M. Different biochemical expression pattern of platelet surface glycoproteins suggests molecular diversity of Glanzmann's thrombasthenia in Iran. Blood Coagul Fibrinolysis. 2013;24(6):613-618. doi:10.1097/MBC.0b013e328360a558

25. Fiore M, Pillois X, Nurden P, Nurden AT, Austerlitz F. Founder effect and estimation of the age of the French gypsy mutation associated with Glanzmann thrombasthenia in Manouch families. Eur J Hum Genet. 2011;19(9):981987. doi:10.1038/ejhg.2011.61

26. Zhou L, Jiang M, Shen H, et al. Clinical and molecular insights into Glanzmann's thrombasthenia in China. Clin Genet. 2018;94 (2):213-220. doi:10.1111/cge.13366

27. Wilcox DA, Paddock CM, Lyman S, Gill JC, Newman PJ. Glanzmann thrombasthenia resulting from a single amino acid substitution between the second and third calcium-binding domains of GPIIb. J Clin Invest. 1995;95(4):1553-1560. doi:10.1172/JCI117828

28. Ferrer M, Fernandez-Pinel M, Gonzalez-Manchon C, Gonzalez J, Ayuso MS, Parrilla R. A mutant (Arg327->His) GPIIb associated to thrombasthenia exerts a dominant negative effect in stably transfected CHO cells. Thromb Haemost. 1996;76(3):292-301. doi:10.1055/s-0038-1650574

29. Grimaldi CM, Chen F, Wu C, Weiss HJ, Coller BS, French DL. Glycoprotein IIb Leu214Pro mutation produces Glanzmann thrombasthenia with both quantitative and qualitative abnormalities in GPIIb/IIIa. Blood. 1998;91(5):1562-1571. doi:10.1182/ blood.V91.5.1562

30. Ambo H, Kamata T, Handa M, et al. Novel point mutations in the aIlb subunit (Phe289->Ser, Glu324->Lys, Gly747Pro) causing thrombasthenic phenotypes in four Japanese patients. $\mathrm{Br}$ $J \quad$ Haematol. 1998;102(3):829-840. doi:10.1046/j.13652141.1998.00824.x

31. Tadokoro S, Tomiyama Y, Honda S, et al. A Gln747->pro substitution in the $\alpha$ IIb subunit is responsible for a moderate $\alpha \operatorname{Ilb} \beta 3$ deficiency in Glanzmann thrombasthenia. Blood. 1998;92 (8):2750-2758. doi:10.1182/blood.V92.8.2750

32. Gonzalez-Manchon C, Fernandez-Pinel M, Arias-Salgado EG, et al. Molecular genetic analysis of a compound heterozygote for the glycoprotein (GP) IIb gene associated with Glanzmann's thrombasthenia: disruption of the 674-687 disulfide bridge in GPIIb prevents surface exposure of GPIIb-IIIa complexes. Blood. 1999;93(3):866-875. doi:10.1182/blood.V93.3.866
33. Arias-Salgado EG, Butta N, Gonzalez-Manchon C, Larrucea $\mathrm{S}$, Ayuso MS, Parrilla R. Competition between normal (674C) and mutant (674R)GPIIb subunits: role of the molecular chaperone BiP in the processing of GPIIb-IIIa complexes. Blood. 2001;97 (9):2640-2647. doi:10.1182/blood.V97.9.2640

34. Basani RB, French DL, Vilaire G, et al. A naturally occurring mutation near the amino terminus of $\alpha \mathrm{IIb}$ defines a new region involved in ligand binding to $\alpha I$ Ilb $\beta 3$. Blood. 2000;95(1):180-188. doi:10.1182/blood.V95.1.180

35. Kamata T, Tieu KK, Irie A, Springer TA, Takada Y. Amino acid residues in the $\alpha$ IIb subunit that are critical for ligand binding to integrin $\alpha \operatorname{IIb} \beta 3$ are clustered in the $\beta$-propeller model. $J$ Biol Chem. 2001;276(47):44275-44283. doi:10.1074/jbc.M107021200

36. Mitchell WB, Li JH, Singh F, et al. Two novel mutations in the $\alpha$ IIb calcium-binding domains identify hydrophobic regions for aIIb33 biogenesis. Blood. 2003;101(6):22682276. doi:10.1182/ blood-2002-07-2266

37. Jayo A, Pabon D, Lastres P, Jimenez V, Gonzalez-Manchon C. Type II Glanzmann thrombasthenia in a compound heterozygote for the $\alpha$ IIb gene. A novel missense mutation in exon 27. Haematologica. 2006;91(10):1352-1359.

38. Goguet M, Narwani TJ, Petermann R, Jallu V, de Brevern AG. In silico analysis of Glanzmann variants of Calf- 1 domain of $\alpha \operatorname{IIb} \beta 3$ integrin revealed dynamic allosteric effect. Sci Rep. 2017;7 (1):8001. doi:10.1038/s41598-017-08408-w

39. Pillois X, Peters P, Segers K, Nurden AT. In silico analysis of structural modifications in and around the integrin $\alpha \mathrm{IIb}$ genu caused by ITGA2B variants in human platelets with emphasis on Glanzmann thrombasthenia. Mol Genet Genomic Med. 2018;6 (2):249-260. doi:10.1002/mgg3.365

40. Grimaldi CM, Chen F, Scudder LE, Coller BS, French DL. A Cys374Tyr homozygous mutation of platelet glycoprotein IIIa $(\beta 3)$ in a Chinese patient with Glanzmann's thrombasthenia. Blood. 1996;88(5):1666-1675. doi:10.1182/blood.V88.5.1666.1666

41. Ambo H, Kamata T, Handa M, et al. Three novel integrin $\beta 3$ subunit missense mutations (H280P, C560F and G579S) in thrombasthenia, including one (H280P prevalent in Japanese patients. Biochem Biophys Res Commun. 1998;251(3):763-768. doi:10.1006/bbrc.1998.9526

42. Ward CN, Kestin AS, Newman PJ. A Leu262Pro mutation in the integrin $\beta 3$ subunit results in an $\alpha \operatorname{Ilb} \beta 3$ complex that binds fibrin but not fibrinogen. Blood. 2000;96(1):161-169. doi:10.1182/ blood.V96.1.161

43. Nair S, Li J, Mitchell WB, Mohanty D, Coller BS, French DL. Two new beta3 integrin mutations in Indian patients with Glanzmann thrombasthenia: localization of mutations affecting cysteine residues in integrin beta3. Thromb Haemost. 2002;88 (3):503-509. doi:10.1160/TH2002880503

44. Westrup D, Santoso S, Follert-Hagendorff K, et al. Glanzmann thrombasthenia Frankfurt I is associated with a point mutation Thr176Ile in the N-terminal region of aIlb subunit integrin. Thromb Haemost. 2004;92(5):1040-1051. doi:10.1160/TH04-030170

45. Morel-Kopp M-C, Melchior C, Chen P, et al. A naturally occurring point mutation in the $\beta 3$ integrin MIDAS-like domain affects differently $\alpha v \beta 3$ and $\alpha$ IIb $\beta 3$ receptor function. Thromb Haemost. 2001;86(6):1425-1434. doi:10.1055/s-0037-1616746

46. Chen P, Melchior C, Brons NHC, Schlegel N, Caen J, Kieffer N. Probing conformational changes in the I-like domain and the cysteine-rich repeat of human $\beta 3$ integrins following disulfide bond disruption by cysteine mutations. Identification of cysteine 598 involved in $\alpha \mathrm{IIb} \beta 3$ activation. $J$ Biol Chem. 2001;276 (42):38628-38635. doi:10.1074/jbc.M105737200

47. Xiong JP, Stehle T, Diefenbach B, et al. Crystal structure of the extracellular segment of the integrin $\alpha v \beta 3$. Science. 2001;294 (5541):339-345. doi:10.1126/science.1064535 
48. Takagi J, Petre B, Walz T, Springer TA. Global conformational rearrangements in integrin extracellular domains in outside-in and inside-out signaling. Cell. 2002;110(5):599-601. doi:10.1016/ S0092-8674(02)00935-2

49. Rosenberg N, Yatuv R, Sobolev V, Peretz H, Zivelin A, Seligsohn U. Major mutations in calf-1 and calf-2 domains of glycoprotein IIb in patients with Glanzmann thrombasthenia enable GPIIb/IIIa complex formation but impair its transport from the endoplasmic reticulum to the Golgi apparatus. Blood. 2003;101(6):4808-4815. doi:10.1182/blood-2002-08-2452

50. Gonzalez-Manchon C, Arias-Salgado EG, Butta N, et al. A novel homozygous splice junction mutation in GPIIb associated with alternative splicing, nonsense-mediated decay of GPIIb-mRNA, and type II Glanzmann's thrombasthenia. J Thromb Haemost. 2003;1(5):1071-1078. doi:10.1046/j.1538-7836.2003.00204.x

51. Jackson DE, White MM, Jennings LK, Newman PJ. A Ser162$>$ Leu mutation within glycoprotein (GP) IIIa (integrin $\alpha \mathrm{IIb} \beta 3$ ) results in an unstable $\alpha \mathrm{IIb} \beta 3$ complex that retains partial function in a novel form of type II Glanzmann thrombasthenia. Thromb Haemost. 1998;80(1):42-48. doi:10.1055/s-0037-1615136

52. Kiyoi T, Tomiyama Y, Honda S, et al. A naturally occurring Tyr143His $\alpha$ IIb mutation abolishes $\alpha \mathrm{IIb} \beta 3$ function for soluble ligands but retains its ability for mediating cell adhesion and clot retraction: comparison with other mutations causing ligandbinding defects. Blood. 2003;101(9):3485-3491. doi:10.1182/ blood-2002-07-2144

53. Flevaris P, Stojanovic A, Gong H, Chishti A, Welch E, Du X. A molecular switch that controls cell spreading and retraction. J Cell Biol. 2007;179(3):553-565. doi:10.1083/jcb.200703185

54. Loftus JC, O'Toole TE, Plow EF, Glass A, Frehlinger AL 3rd, Ginsberg $\mathrm{MH}$. A $\beta 3$ integrin mutation abolishes ligand binding and alters divalent-cation dependent conformation. Science. 1990;249(4971):915-918. doi:10.1126/science. 2392682

55. Bajt ML, Ginsberg MH, Frelinger AL, Berndt MC, Loftus JC. A spontaneous mutation of integrin $\alpha \mathrm{IIb} \beta 3$ (platelet glycoprotein IIb-IIIa) helps define a ligand binding site. J Biol Chem. 1992;267 (6):3789-3794. doi:10.1016/S0021-9258(19)50595-6

56. Lanza F, Stierle A, Fournier D, et al. A new variant of Glanzmann's thrombasthenia (Strasbourg I). Platelets with functionally defective glycoprotein IIb-IIIa complexes and a glycoprotein IIIa ${ }^{214} \mathrm{Arg}->^{214} \mathrm{Trp}$ mutation. $J$ Clin Invest. 1992;89(6):1995-2004. doi:10.1172/JCI115808

57. Honda S, Tomiyama Y, Shiraga M, et al. A two-amino acid insertion in the Cys146-Cys167 loop of the $\alpha$ IIb subunit is associated with a variant of Glanzmann thrombasthenia. J Clin Invest. 1998;102(6):1183-1192. doi:10.1172/JCI3206

58. Chen YP, Djaffar I, Pidard D, et al. Ser-752-Pro mutation in the cytoplasmic domain of integrin beta3 subunit and defective activation of platelet integrin alphaIIbbeta3 (glycoprotein IIb-IIIa) in a variant of Glanzmann thrombasthenia. Proc Natl Acad Sci USA. 1992;89(21):10169-10173. doi:10.1073/pnas.89.21.10169

59. Nurden P, Poujol C, Winckler J, Combrié R, Caen JP, Nurden AT. A Ser752->Pro substitution in the cytoplasmic domain of beta3 in a Glanzmann thrombasthenia variant fails to prevent interactions between the alphaIIbbeta3 integrin and the granule pool of fibrinogen. $B r J$ Haematol. 2002;118(4):1143-1151. doi:10.1046/ j.1365-2141.2002.03758.x

60. Wang R, Shattil SJ, Ambruso DR, Newman PJ. Truncation of the cytoplasmic domain of beta3 in a variant form of Glanzmann thrombasthenia abrogates signaling through the integrin alpha(IIb)beta3 complex. J Clin Invest. 1997;100(9):2393-2403. doi:10.1172/JCI119780

61. Vinogradova O, Velyvis A, Velyvienne A, et al. A structural mechanism of integrin alpha(IIb)beta(3) "inside-out" activation as regulated by its cytoplasmic face. Cell. 2002;110(5):587-597. doi:10.1016/S0092-8674(02)00906-6
62. Ruiz C, Liu C-Y, Sun Q-H, et al. A point mutation in the cysteinerich domain of glycoprotein (GP) IIIa results in the expression of a GPIIb-IIIa $(\alpha \mathrm{IIb} \beta 3)$ integrin receptor locked in a high-affinity state and a Glanzmann thrombasthenia-like phenotype. Blood. 2001;98(8):2432-2441. doi:10.1182/blood.V98.8.2432

63. Mor-Cohen R, Rosenberg N, Peretz H, et al. Disulfide bond disruption by a $\beta 3$-Cys549Arg mutation in six Jordanian families with Glanzmann thrombasthenia causes diminished production of constitutively active $\alpha \mathrm{IIb} \beta 3$. Thromb Haemost. 2007;98:1257-1265. doi:10.1160/TH07-04-0248

64. Kamata T, Ambo H, Puzon-McLaughin W, et al. Critical cysteine residues for regulation of integrin $\alpha \operatorname{IIb} \beta 3$ are clustered in the epidermal growth factor domains of the $\beta 3$ subunit. Biochem J. 2004;378(3):1079-1082. doi:10.1042/bj20031701

65. Vanhoorelbeke K, De Meyer SF, Pareyn I, et al. The novel S527F mutation in the integrin $\beta 3$ chain induces a high affinity $\alpha \operatorname{IIb} \beta 3$ receptor by hindering adoption of the bent conformation. $J$ Biol Chem. 2009;284(22):14914-14920. doi:10.1074/jbc.M809167200

66. Gonzalez-Manchon C, Butta N, Larrucea S, et al. A variant thrombasthenic phenotype associated with compound heterozygosity of integrin $\beta 3$-subunit (Met124Val) $\beta 3$ alters the subunit dimerization rendering a decreased number of constitutive active $\alpha \mathrm{IIb} \beta 3$ receptors. Thromb Haemost. 2004;92(6):1377-1386. doi:10.1160/TH04-06-0380

67. Hardisty R, Pidard D, Cox A, et al. A defect of platelet aggregation associated with an abnormal distribution of glycoprotein IIb-IIIa complexes within the platelet: the cause of a lifelong bleeding disorder. Blood. 1992;80(3):696-708. doi:10.1182/ blood.V80.3.696.696

68. Peyruchaud O, Nurden AT, Milet S, et al. An Arg995 ${ }^{\circledR}$ to Gln (Q) aminoacid substitution in the GFFKR sequence of the cytoplasmic domain of the integrin ${ }_{\text {IIb }}$ subunit in a patient with an unusual variant form of Glanzmann's thrombasthenia. Blood. 1998;92 (11):4178-4187. doi:10.1182/blood.V92.11.4178

69. Hughes PE, Diaz-Gonzalez F, Leong L, et al. Breaking the integrin hinge. A defined structural constraint regulates integrin signaling. J Biol Chem. 1996;271(12):6571-6574. doi:10.1074/jbc.271.12.6571

70. Kunishima S, Kashiwagi H, Otsu M, et al. Heterozygous ITGA2B R995W mutation inducing constitutive activation of the alphaIIbbeta3 receptor affects proplatelet formation and causes congenital macrothrombocytopenia. Blood. 2011;117 (2):5479-5484. doi:10.1182/blood-2010-12-323691

71. Ghevaert C, Salamann A, Watkins NA, et al. A nonsynonymous SNP in the ITGB3 gene disrupts the conserved membrane proximal cytoplasmic salt bridge in the alphallbbeta3 integrin and cosegregates dominantly with abnormal proplatelet formation and the macrothrombocytopenia. Blood. 2008;111 (7):3407-3414. doi:10.1182/blood-2007-09-112615

72. Favier M, Bordet J-C, Favier R, et al. Mutations of the $\alpha \mathrm{IIb} / \beta 3$ intracytoplasmic salt bridge cause macrothrombocytopenia and enlarged platelet $\alpha$-granules. Am J Haematol. 2017;93 (2):195-204. doi:10.1002/ajh.24958

73. Morais S, Oliveira S, Lau C, et al. $\alpha \operatorname{IIb} \beta 3$ variants in ten families with autosomal dominant macrothrombocytopenia: expanding the mutational and clinical spectrum. PLoS One. 2020;15(12): e0235136. doi:10.1371/journal.pone.0235136

74. Gresele P, Falcinelli E, Giannini S, et al. Dominant inheritance of a novel integrin beta3 mutation associated with a hereditary macrothrombocytopenia and platelet dysfunction in two Italian families. Haematologica. 2009;94(5):663-669. doi:10.3324/ haematol.2008.002246

75. Jayo A, Conde I, Lastres P, et al. L718P mutation in the membrane-proximal cytoplasmic tail of beta3 promotes abnormal alphaIIbbeta3 clustering and lipid domain coalescence and associates with a thrombasthenia-like phenotype. Haematologica. 2010;95(7):1158-1166. doi:10.3324/haematol.2009.018572 
76. Nurden P, Bordet JC, Pillois X, Nurden AT. An intracytoplasmic $\beta 3$ Leu718 deletion in a patient with a novel platelet phenotype. Blood Adv. 2017;1(8):494-499. doi:10.1182/bloodadvances.20 16002808

77. Nurden AT, Nurden P. Inherited thrombocytopenias: history advances and perspectives. Haematologica. 2020;105 (8):2004-2019. doi:10.3324/haematol.2019.233197

78. Nurden P, Stritt S, Favier R, Nurden AT. Inherited platelet diseases with normal platelet count: phenotypes, genotypes and diagnostic strategy. Haematologica. 2021;106(2):337-350. doi:10.3324/haematol.2020.248153

79. Peretz H, Rosenberg N, Landau M, et al. Molecular diversity of Glanzmanns thrombasthenia in Southern India: new insights into mRNA splicing and structure-function correlations of alphaIIbbeta3 integrin (ITGA2B, ITGB3). Hum Mutat. 2006;27 (4):359-369. doi:10.1002/humu.20304

80. Nelson EJR, Nair SC, Peretz H, et al. Diversity of Glanzmann thrombasthenia in Southern India: 10 novel mutations identified among 15 unrelated patients. J Throm Haemost. 2006;4 (8):1730-1737. doi:10.1111/j.1538-7836.2006.02066.x

81. Jallu V, Dusseaux M, Panzer S, et al. $\alpha \operatorname{IIb} \beta 3$ integrin: new allelic variants in Glanzmann thrombasthenia. Effects on ITGA2B and ITGB3 mRNA splicing, expression, and structure-function. Hum Mutat. 2009;31(3):237-246. doi:10.1002/humu.21179

82. Sandrock-Lang K, Oldenburg J, Wiegering V, et al. Characterization of patients with Glanzmann thrombasthenia and identification of 17 novel mutations. Thromb Haemost. 2015;113:782-791. doi:10.1160/TH14-05-0479

83. Robert P, Canault M, Farnarier C, et al. A novel leukocyte adhesion deficiency III variant: kindlin-3 deficiency results in integrin and non-integrin related defects in late steps of leukocyte adhesion. J Immunol. 2011;186(9):5273-5283. doi:10.4049/ jimmunol.1003141

84. Desai A, Bergmeier W, Canault M, et al. Phenotype analysis and clinical management in a large family with a novel truncating mutation in RASGRP2, the CaLDAG-GEFI encoding gene. Res Pract Thromb Haemost. 2017;1(1):128-133. doi:10.1002/ rth2.12019

85. Podolnikova NP, Gorkun OV, Loreth RM, Yee VC, Lord ST, Ugarova TP. A cluster of basic amino acid residues in the $\gamma 370-380$ sequence of fibrinogen comprises a binding site for platelet integrin $\alpha \mathrm{IIb} \beta 3$ (GPIIb/IIIa). Biochemistry. 2005;44 (51):1620-2630. doi:10.1021/bi051581d

86. Podolnikova NP, Yakovlev S, Yakubenko VP, Wang X, Gorkun OV, Ugarova TP. The interaction of integrin $\alpha \operatorname{IIb} \beta 3$ with fibrin occurs through multiple binding sites in the $\alpha \mathrm{IIb} \beta$ propeller domain. J Biol Chem. 2014;289(4):2371-2383. doi:10.1074/jbc.M113.518126

87. Mammadova-Bach E, Ollivier V, Loyau S, et al. Platelet glycoprotein VI binds to polymerized fibrin and promotes thrombin generation. Blood. 2015;126:683-691. doi:10.1182/blood-201502-629717

88. Alshehri OM, Hughes CE, Montague S, et al. Fibrin activates GPVI in human and mouse platelets. Blood. 2015;126:1601-1608. doi:10.1182/blood-2015-04-641654

89. Onsalaer M-B, Hardy AT, Wilson C, et al. Fibrin and D-dimer bind to monomeric GPVI. Blood Adv. 2017;1(19):1495-1504. doi:10.1182/bloodadvances.2017007732

90. Perrella G, Huang J, Provenzale I, et al. Nonredundant roles of platelet glycoprotein VI and integrin $\alpha \operatorname{IIb} \beta 3$ in fibrin-mediated microthrombus formation. Arterioscler Thromb Vasc Biol. 2021;41(2):e97-e111. doi:10.1161/ATVBAHA.120.314641

91. Nurden AT. Clinical significance of altered collagen receptor functioning in platelets with emphasis on GPVI. Blood Rev. 2019;38:100592. doi:10.1016/j.blre.2019.100592
92. McGregor JL, Clemetson KJ, James E, et al. Glycoproteins of platelet membranes from Glanzmann's thrombasthenia. A comparison with normal using carbohydrate-specific or proteinspecific labeling techniques and high-resolution two-dimensional gel electrophoresis. Eur J Biochem. 1981;116(2):379-388. doi:10.1111/j.1432-1033.1981.tb05346.x

93. Loroch S, Trabold K, Gambaryan S, et al. Alterations of the platelet proteome in type I Glanzmann thrombasthenia caused by different homozygous delG frameshift mutations in ITGA2B. Thromb Haemost. 2017;117(3):556-569. doi:10.1160/TH16-07-0515

94. Blair TA, Michelson AD, Frelinger AL III. Mass cytometry reveals distinct platelet subtypes in healthy subjects and novel alterations in surface glycoproteins in Glanzmann thrombasthenia. Sci Rep. 2018;8(1):10300. doi:10.1038/s41598018-28211-5

95. Megy K, Downes K, Simeoni I, et al. Curated disease-causing genes for thrombotic, and platelet disorders; Communication from the SSC of the ISTH. J Thromb Haemost. 2019;17 (8):1253-1260. doi:10.1111/jth.14479

96. Ver Donck F, Downes K, Freson K. Strengths and limitations of high-throughput sequencing for the diagnosis of inherited bleeding and platelet disorders. J Thromb Haemost. 2020;18 (8):1839-1845. doi:10.1111/jth.14945

97. Buitrago L, Rendon A, Liang Y, et al.,;. $\alpha \operatorname{IIb} \beta 3$ variants defined by next-generation sequencing: predicting variants likely to cause Glanzmann thrombasthenia. Proc Natl Acad Sci USA. 2015;112: E1898-1907. doi:10.1073/pnas.1422238112

98. Pillois X, Nurden AT. Linkage disequilibrium amongst ITGA2B and ITGB3 gene variants in patients with Glanzmann thrombasthenia confirms that most disease-causing mutations are recent. Br J Haematol. 2016;175(4):686-695. doi:10.1111/ bjh. 14283

99. Di Minno G, Zotz RB, d'Oiron R, et al. The international, prospective Glanzmann Thrombasthenia Registry: treatment modalities and outcomes of non-surgical bleeding episodes in patients with Glanzmann thrombasthenia. Haematologica. 2015;100 (8):1031-1037. doi:10.3324/haematol.2014.121475

100. Poon MC, Di Minno MN, d'Oiron R, Zotz RB. New insights into the treatment of Glanzmann thrombasthenia. Transfus Med Rev. 2016;30(2):92-99. doi:10.1016/j.tmrv.2016.01.001

101. Al-Battat S, Rand ML, Bouskill V, et al. Glanzmann thrombasthenia platelets compete with transfused platelets, reducing the haemostatic impact of platelet transfusions. Br J Haematol. 2018;81 (3):410-413. doi:10.1111/bjh.14623

102. Fiore M, Firah N, Pillois X, Nurden P, Heilig R, Nurden AT, Natural history of platelet antibody formation against $\alpha \operatorname{IIb} \beta 3$ in a French cohort of Glanzmann thrombasthenia patients. Haemophilia. 2012;18(3):201-209. doi:10.1111/j.13652516.2011.02744.x

103. Nurden AT. Acquired antibodies to $\alpha$ IIb $\beta 3$ in Glanzmann thrombasthenia; From transfusion and pregnancy to bone marrow transplants and beyond. Transfus Med Rev. 2018;S0887-7963(18)30037-3. doi:10.1016/j.tmrv.2018.05.002

104. Leticée N, Kaplan C, Lémery D. Pregnancy in mother with Glanzmann's thrombasthenia and isoantibody against GP IIbIIIa: is there a foetal risk? Eur J Obstet Gynecol Reprod Biol. 2005;121(2):138-142. doi:10.1016/j.ejogrb.2005.02.011

105. Santoso S, Wihadmadyatami H, Bakchtoul T, et al. Antiendothelial $\alpha v \beta 3$ antibodies are a major cause of intracranial bleeding in fetal-neonatal alloimmune thrombocytopenia. Arterioscler Thromb Vasc Biol. 2016;36(8):1517-1524. doi:10.1161/ATVBAHA.116.307281

106. Fiore M, Bayat B, Phuangtham R, et al. Immunization against both $\alpha \mathrm{IIb} \beta 3$ and $\alpha v \beta 3$ in Glanzmann thrombasthenia patients carrying the French gypsy mutation. J Thromb Haemost. 2021;19(1):255-261. doi:10.1111/jth.15117 
107. Guillet B, Bayart S, Pillois X, Nurden P, Caen JP, Nurden AT. A Glanzmann thrombasthenia family associated with a TUBB1-related macrothrombocytopenia. J Thromb Haemost. 2019;17(12):2221. doi:10.1111/jth.14622

108. Deshpande R, Shanbhag S, Jadii A, Shetty S. A rare case of Glanzmann's thrombasthenia and factor VII deficiency due to a combination of pathogenic and non-pathogenic gene variants. Haemophilia. 2020;26(1):e26-e27. doi:10.1111/hae.13898

109. Owaidah T, Saleh M, Baz B, et al. Molecular yield of targeted sequencing for Glanzmann thrombasthenia patients. NPJ Genom Med. 2019;4:4. doi:10.1038/s41525-019-0079-6

110. Bellucci S, Damaj G, Boval B, et al. Bone marrow transplantation in severe Glanzmann's thrombasthenia with antiplatelet alloimmunization. Bone Marrow Transplant. 2000;25(3):327-330. doi:10.1038/sj.bmt.1702139

111. Flood V, Johnson FL, Boshkov LK, et al. Sustained engraftment post bone marrow transplant despite anti-platelet antibodies in Glanzmann thrombasthenia. Pediatr Blood Cancer. 2005;45 (7):971-975. doi:10.1002/pbc.20365

112. Fang J, Hodivala-Dilke K, Johnson BD, et al. Therapeutic expression of the platelet-specific integrin, $\alpha \operatorname{IIb} \beta 3$, in a murine model for Glanzmann thrombasthenia. Blood. 2005;106(8):2671-2679. doi:10.1182/blood-2004-12-4619
113. Fang J, Jensen ES, Boudreaux MK, et al. Platelet gene therapy improves hemostatic function for integrin $\alpha \mathrm{IIb} \beta 3$-deficient dogs. Proc Natl Acad Sci USA. 2011;108(23):9583-9588. doi:10.1073/ pnas. 1016394108

114. Sullivan KA, Mills JA, Koukouritaki SB, et al. High-level transgene expression in induced pluripotent stem-cell derived megakaryocytes: correction of Glanzmann thrombasthenia. Blood. 2013;124(5):753-757.

115. Hu L, Du L, Zhao Y, et al. Modeling Glanzmann thrombasthenia using patient specific iPSCs and restoring platelet aggregation function by CD41 overexpression. Stem Cell Res. 2017;2:14-20. doi:10.1016/j.scr.2017.02.003

116. Zhang N, Zhi H, Curtis BR, et al. CRISPR/Cas9-mediated conversion of human platelet alloantigen allotypes. Blood. 2016;127 (6):675-680. doi:10.1182/blood-2015-10-675751

117. Engin MMN. Bleeding disorders associated with abnormal platelets: glanzmann thrombasthenia and Bernard-Soulier syndrome Platelets. 2020. doi:10.5772/intechopen.9329
Journal of Blood Medicine

\section{Publish your work in this journal}

The Journal of Blood Medicine is an international, peer-reviewed, open access, online journal publishing laboratory, experimental and clinical aspects of all aspect pertaining to blood based medicine including but not limited to: Transfusion Medicine; Blood collection, Donor issues, Transmittable diseases, and Blood banking logistics; Immunohematology; Artificial and alternative blood based therapeutics; Hematology; Biotechnology/nanotechnology of blood related medicine; Legal aspects of blood medicine; Historical perspectives. The manuscript management system is completely online and includes a very quick and fair peer-review system. Visit http://www.dovepress.com/testimonials.php to read real quotes from published authors. 